\title{
Sirtuin Modulators in Cellular and Animal Models of Human Diseases
}

\author{
Jun Young Hong ${ }^{1}$ and Hening Lin ${ }^{1,2 *}$ \\ ${ }^{1}$ Department of Chemistry and Chemical Biology, Cornell University, Ithaca, NY, United States, ${ }^{2}$ Department of Chemistry and \\ Chemical Biology, Howard Hughes Medical Institute, Cornell University, Ithaca, NY, United States
}

OPEN ACCESS

Edited by: Jose Thaiparambil, Weill Cornell Medical College of Cornell University, United States

Reviewed by: Pedro Gomes,

University of Coimbra, Portugal Carlos Escande,

Institut Pasteur de Montevideo,

Uruguay

Hou-Zao Chen,

Chinese Academy of Medical Sciences and Peking Union Medical

College, China

${ }^{*}$ Correspondence: Hening Lin h/379@cornell.edu

Specialty section: This article was submitted to Translational Pharmacology, a section of the journal

Frontiers in Pharmacology

Received: 02 July 2021

Accepted: 24 August 2021 Published: 28 September 2021

Citation:

Hong JY and Lin H (2021) Sirtuin Modulators in Cellular and Animal Models of Human Diseases. Front. Pharmacol. 12:735044. doi: 10.3389/fphar.2021.735044
Sirtuins use $\mathrm{NAD}^{+}$to remove various acyl groups from protein lysine residues. Through working on different substrate proteins, they display many biological functions, including regulation of cell proliferation, genome stability, metabolism, and cell migration. There are seven sirtuins in humans, SIRT1-7, each with unique enzymatic activities, regulatory mechanisms, subcellular localizations, and substrate scopes. They have been indicated in many human diseases, including cancer, neurodegeneration, microbial infection, metabolic and autoimmune diseases. Consequently, interests in development of sirtuin modulators have increased in the past decade. In this brief review, we specifically summarize genetic and pharmacological modulations of sirtuins in cancer, neurological, and cardiovascular diseases. We further anticipate this review will be helpful for scrutinizing the significance of sirtuins in the studied diseases.

Keywords: sirtuin, inhibitor, activator, cancer, neurodeganaration, cardiovacsular diseases, SIRT1, SIRT2

\section{INTRODUCTION}

Sirtuins, the class III histone deacetylase, use $\mathrm{NAD}^{+}$to remove various acyl modifications on protein lysine residues (Sauve et al., 2001; Sauve et al., 2006; Feldman et al., 2012). In humans, there are seven sirtuins (SIRT1-7), with different acyl group specificities and subcellular localizations. Through deacylation, sirtuins regulate a wide range of biological functions, such as cell proliferation, metabolism, transcription, apoptosis, and cell signaling (Avalos et al., 2005; Machado de Oliveira et al., 2012; Morris, 2013; Hu et al., 2014; Jing and Lin, 2015; Bheda et al., 2016; Blank et al., 2017; Cha et al., 2017; Kosciuk et al., 2019; Wang and Lin, 2021). Consequently, sirtuins have been linked to various diseases, including cancer, neurological, and cardiovascular diseases (Borradaile and Pickering, 2009; Haigis and Sinclair, 2010; Hu et al., 2014; Fujita and Yamashita, 2018). Many sirtuin activators and inhibitors have been designed and used in cellular and animal studies. In this review, we summarized sirtuin modulators that showed promising therapeutic effects in cancer, neurological, and cardiovascular disease models.

The seven mammalian sirtuins localize to different cellular compartments. SIRT1, SIRT6, and SIRT7 mainly reside in the nucleus, but SIRT1 and SIRT6 are also found in the cytoplasm. SIRT2 is mainly in the cytoplasm. SIRT3, SIRT4, and SIRT5 are primarily located in the mitochondria (Feldman et al., 2012). Yet, under certain conditions, like cell division or stress, several sirtuins may change their cellular locations (North and Verdin, 2007; Tanno et al., 2007; Nishida et al., 2015).

All seven sirtuins use a similar mechanism to catalyze lysine deacylation (Avalos et al., 2005; Feldman et al., 2015; Wang and Lin, 2021). First, the amide group of the acyl lysine attacks $\mathrm{C} 1$ of the $\mathrm{NAD}^{+}$ribose and releases nicotinamide (Figure 1). This forms a covalent $\mathrm{Cl}^{\prime}$-O-alkylamidate intermediate. Then, the conserved histidine deprotonates the $3^{\prime}$-hydroxyl group of the $\mathrm{NAD}^{+}$ribose, which deprotonates the $2^{\prime}$-hydroxyl group. The deprotonated $2^{\prime}$-hydroxyl group attacks the $\mathrm{C} 1^{\prime}$-Oalkylamidate intermediate, forming a $1^{\prime}, 2^{\prime}$-cyclic intermediate. The acyl group is transferred to the 

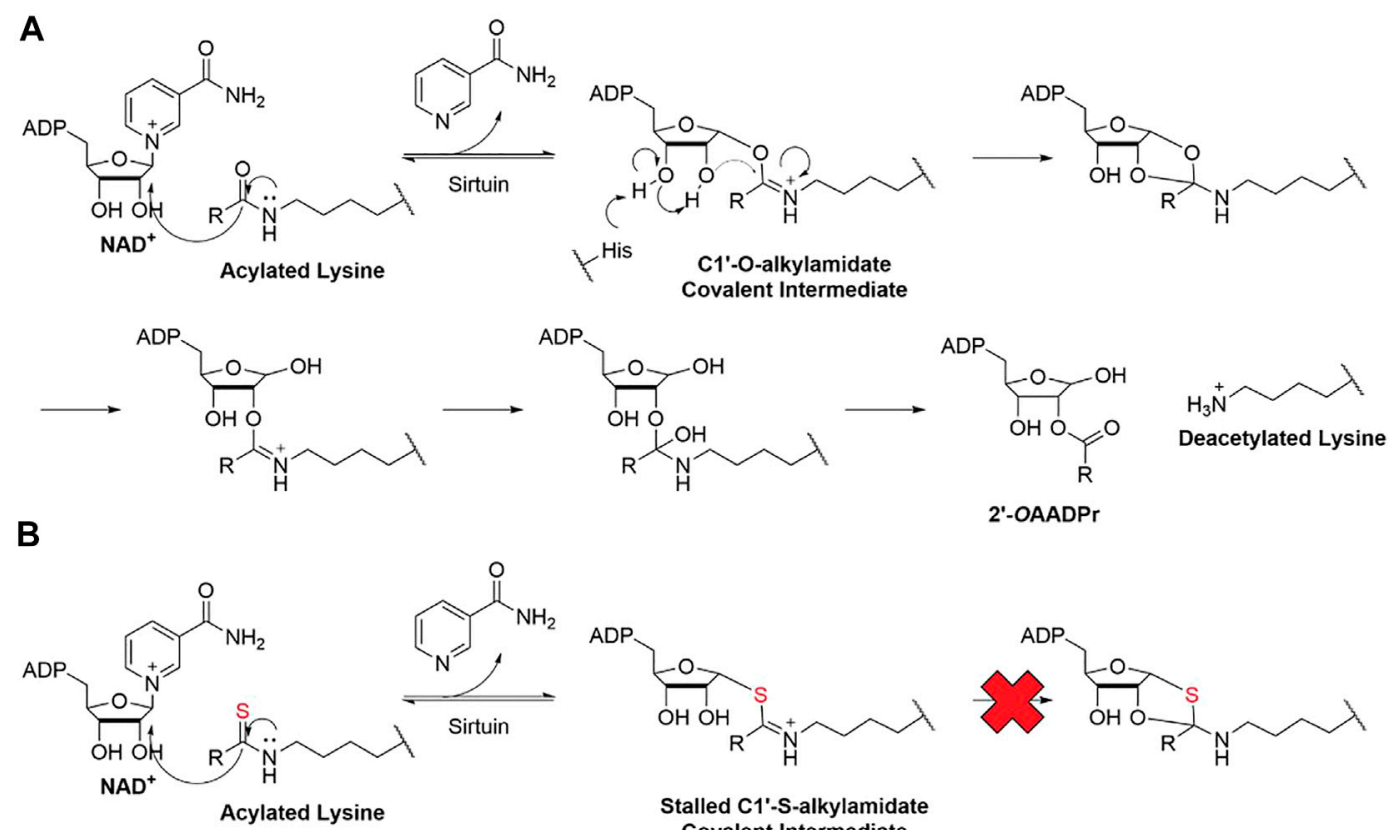

Covalent Intermediate

FIGURE 1 | (A) Schematic summary of sirtuin deacylation mechanism. (B) Schematic summary of mechanism-based inhibition of sirtuin

$2^{\prime}$-hydroxyl group and releases the deacylated lysine product and 2'-O-acyl ADP-ribose (Avalos et al., 2005; Feldman et al., 2015; Wang and Lin, 2021).

Even though SIRT1-7 operate through a similar catalytic mechanism, different sirtuins prefer different acyl substrates due to differences in their substrate pockets. SIRT1 and SIRT3 remove acetyl and long-chain fatty acyl groups from lysine in vitro, but so far known physiological substrates are all deacetylation substrates (Feldman et al., 2012; Teng et al., 2015). SIRT2 removes acetyl, long-chain fatty acyl, 4oxononanoyl, and benzoyl groups (Feldman et al., 2012; Teng et al., 2015; Jin et al., 2016; Huang et al., 2018). SIRT4 removes lipoyl, biotinyl, methylglutaryl, hydroxymethylglutaryl, and 3methylglutaconyl groups (Mathias et al., 2014; Anderson et al., 2017; Kumar and Lombard, 2017; Pannek et al., 2017). SIRT5 removes charged malonyl, succinyl, and glutaryl groups (Du et al., 2011). SIRT6 and SIRT7 remove acetyl and long-chain fatty acyl groups (Zhang et al., 2016; Tong et al., 2017). Both acetyl and long-chain fatty acyl substrates were known for SIRT6, but only physiological acetyl substrates are known for SIRT7.

Many modulators are strategically designed to target different sirtuins and generate beneficial effects in human disease models. As many recently published research articles emphasized the importance of sirtuins in cancer, neurological, and cardiovascular diseases, we have specifically chosen these in this review. We summarize the various sirtuin modulators that have been developed, focusing on those that have demonstrated biological effects in cellular or animal models. Because one common concern about small molecules is whether their biological activity is through on-target effect or not, we will emphasize whether the sirtuin modulators' biological activity is confirmed by other means, such as knockdown, knockout, or overexpression of the sirtuin being targeted. Accordingly, we will spend more attention describing the sirtuin modulators for which the biological activity has been confirmed by other methods.

Previous reports focused on analyzing the roles of sirtuins and a few selected modulators (Chalkiadaki and Guarente, 2015; Gomes et al., 2019). Thus, our review with a more extensive summary of direct sirtuin modulators can help the readers to choose a suitable compound for their experiments. In addition to Table 1 with the compound structure, inhibition profile, and results from biological studies, we added tables that list cancer cell lines affected by the sirtuin modulators (Tables 2-6). This way, this review can serve as an initial useful guideline for those thinking of using sirtuin modulators in their studies.

\section{OVERVIEW OF SIRTUIN MODULATORS}

Numerous activators and inhibitors of sirtuins have been synthesized. Before discussing the evaluation of the sirtuin modulators in the disease models, we will briefly provide an overview of the sirtuin modulators and their efficiency. The structures and other information of these modulators are summarized in Table $\mathbf{1 .}$

There are several compounds that regulates the cellular level of $\mathrm{NAD}^{+}$and consequently modulate sirtuins. Adding precursors of $\mathrm{NAD}^{+}$like nicotinamide riboside (NR) or nicotinamide mononucleotide $(\mathrm{NMN})$ to the cells increased the overall $\mathrm{NAD}^{+}$level, thereby activating sirtuins (Bonkowski and Sinclair, 2016; Trammell et al., 2016). Furthermore, inhibiting $\mathrm{CD} 38$, which converts $\mathrm{NAD}^{+}$to various products, with apigenin 


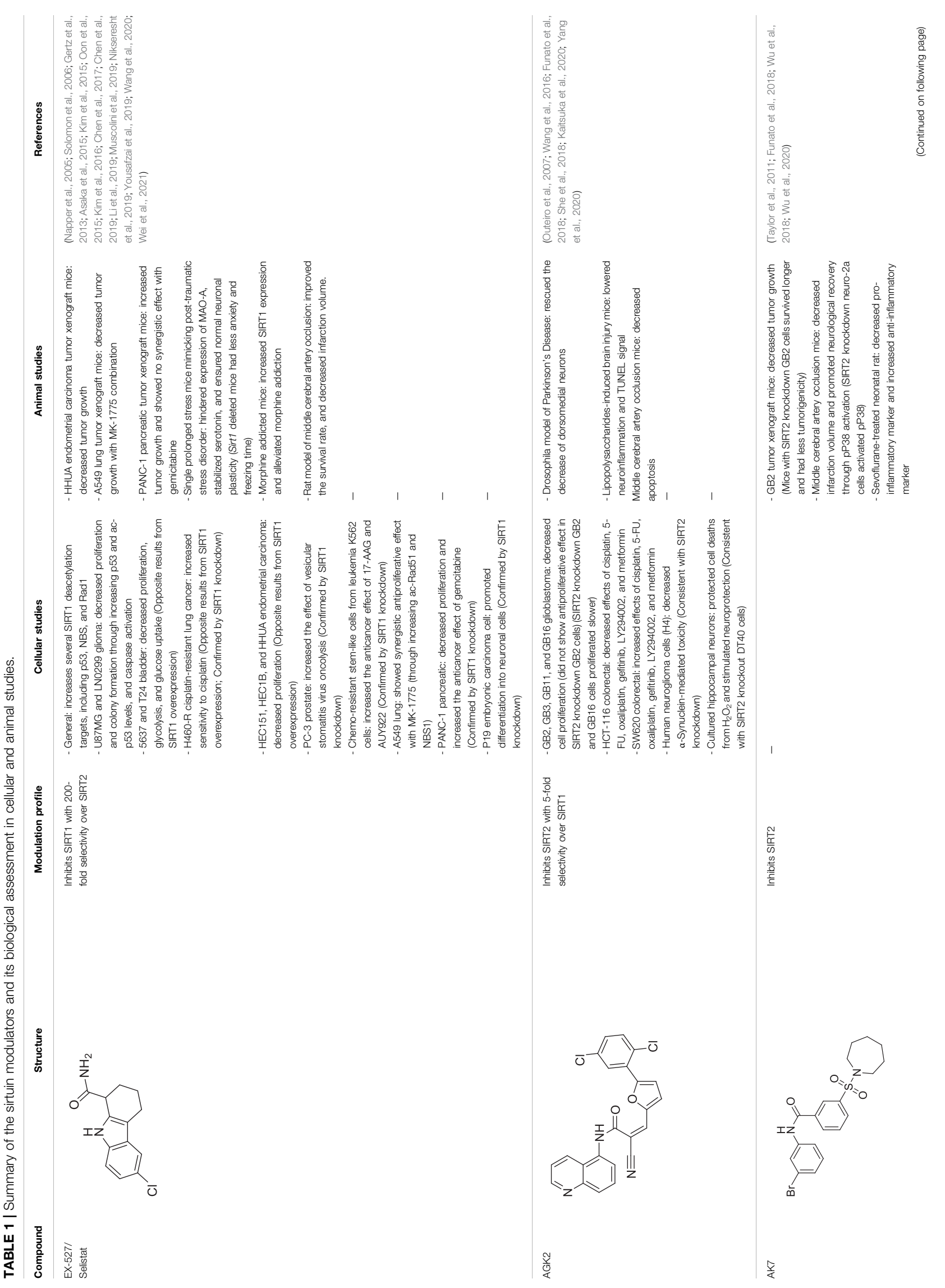




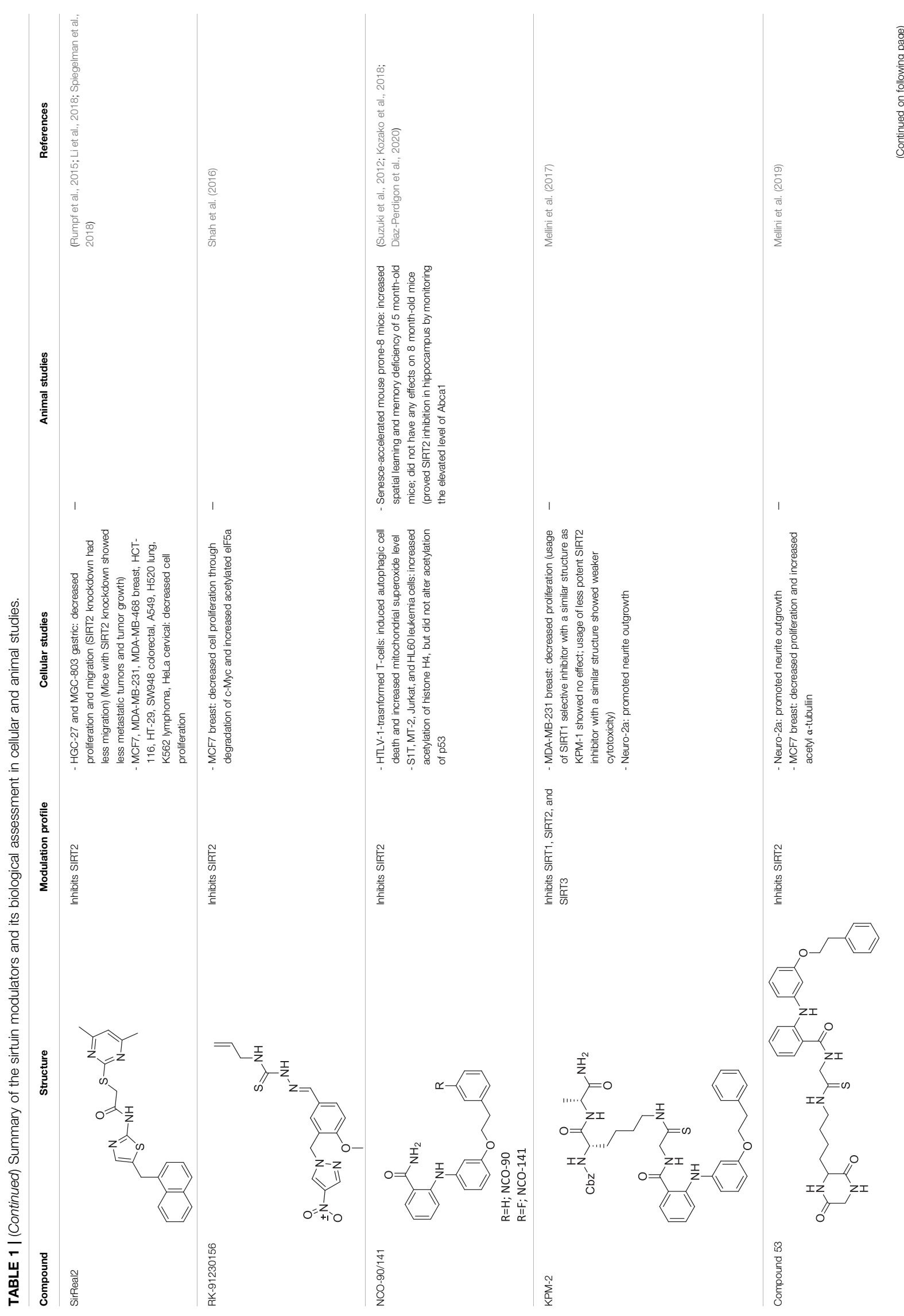




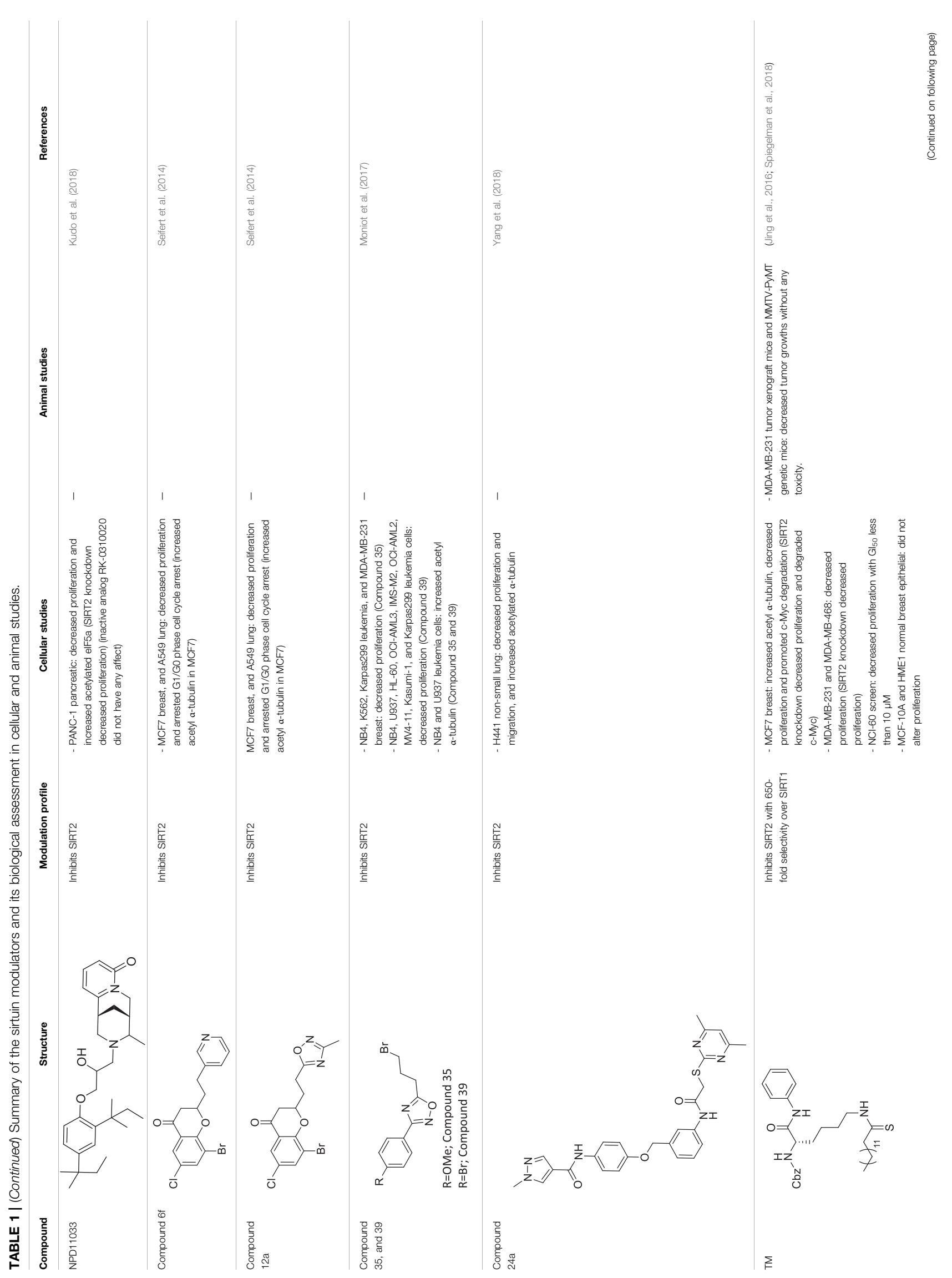




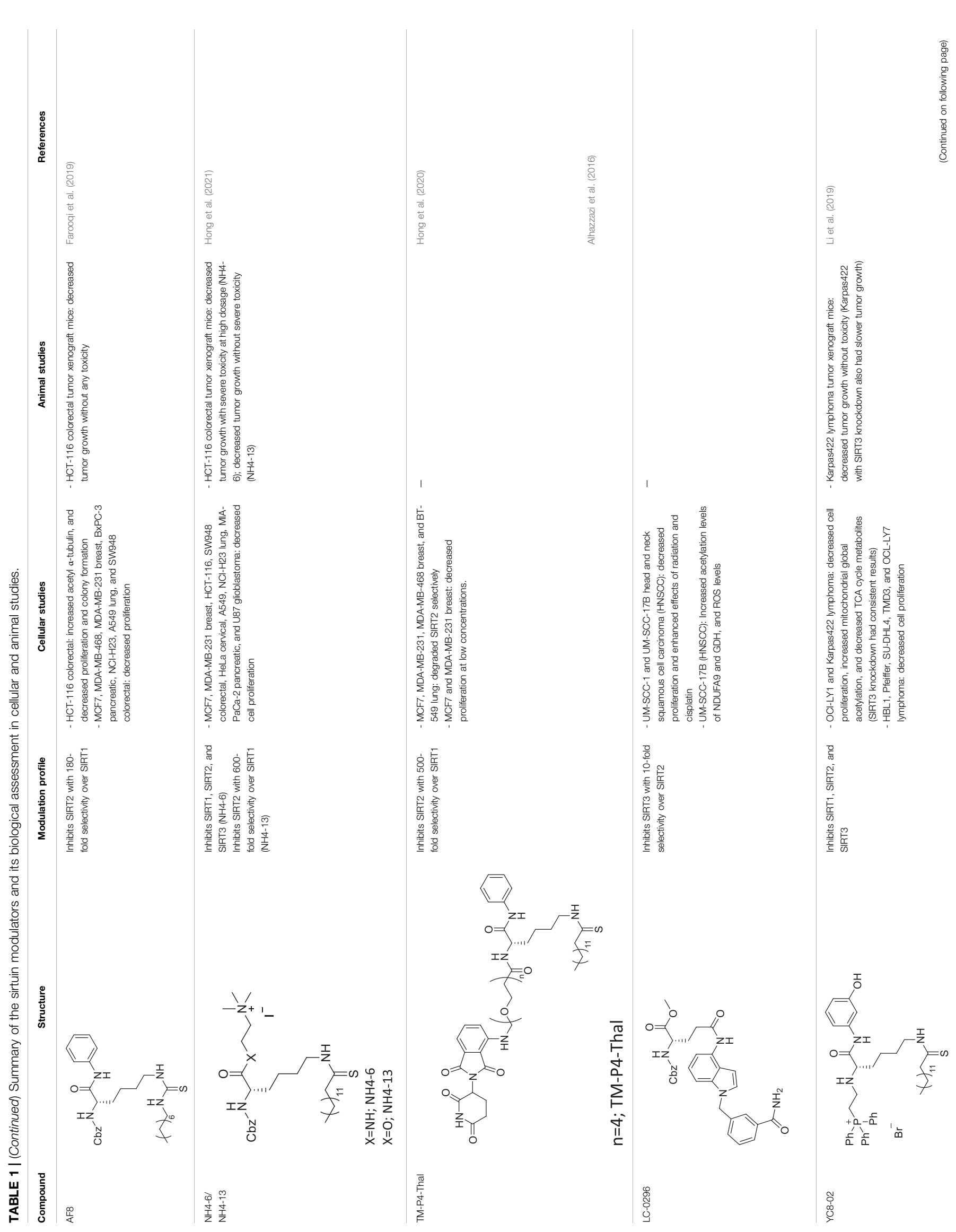




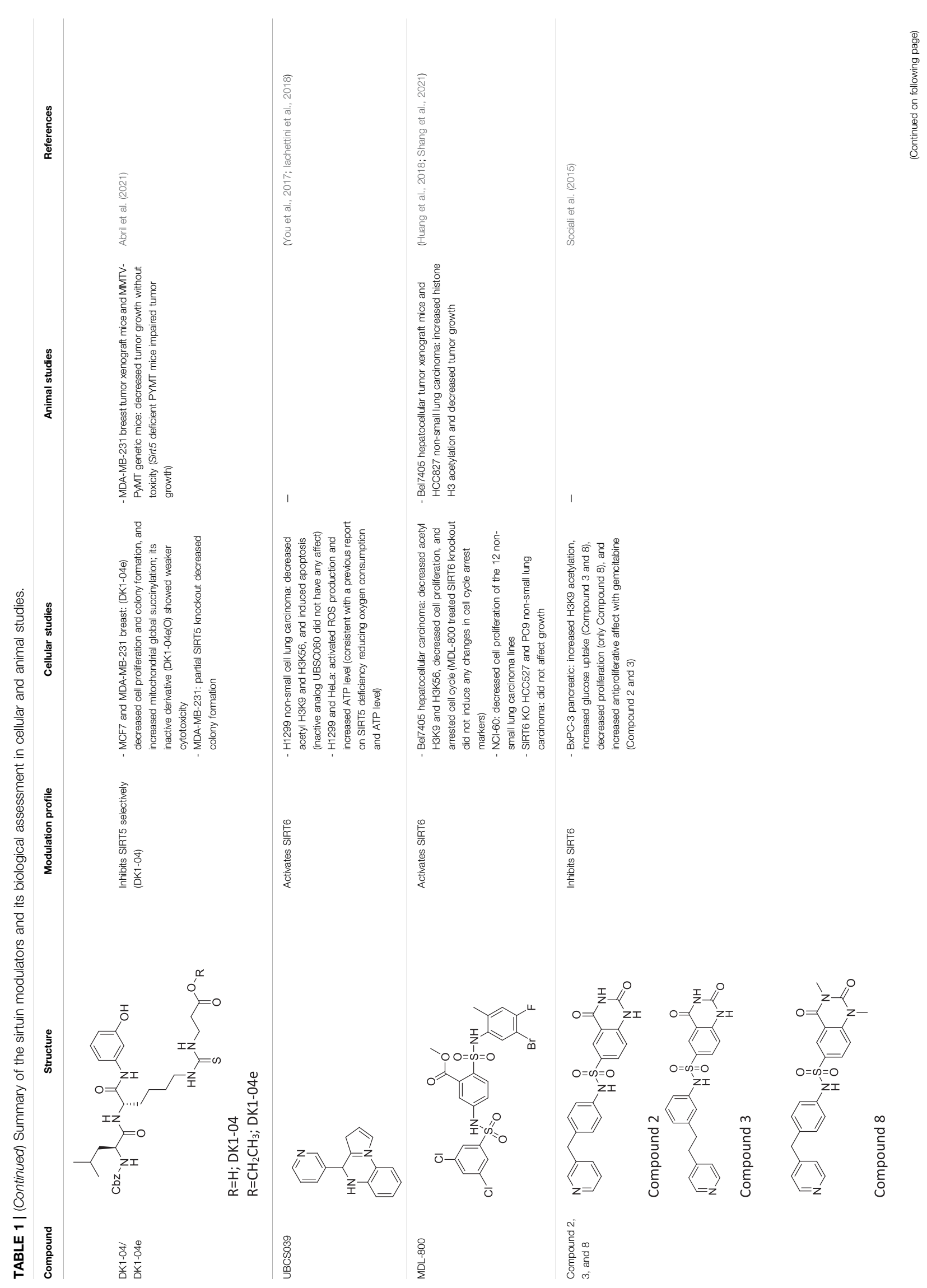




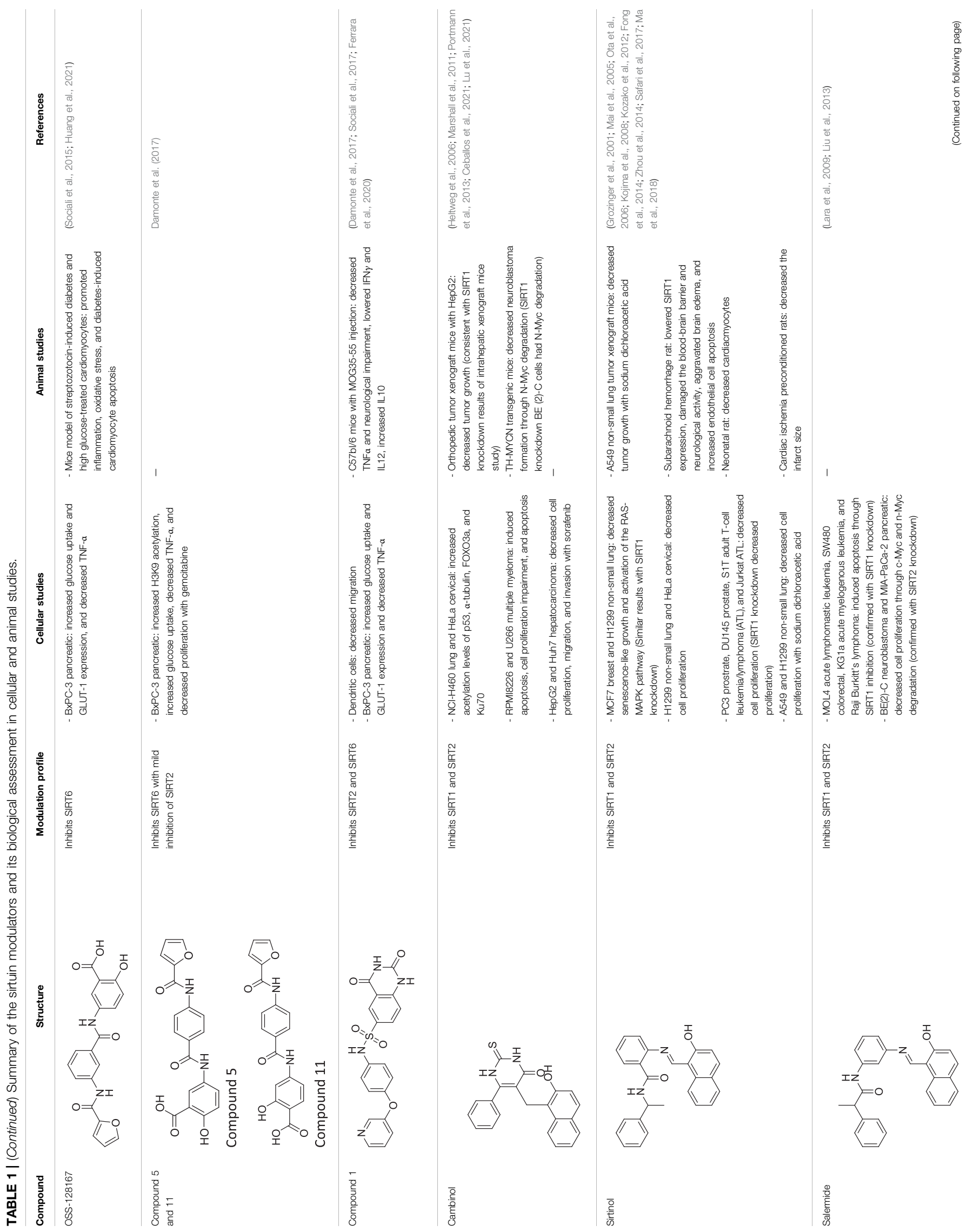




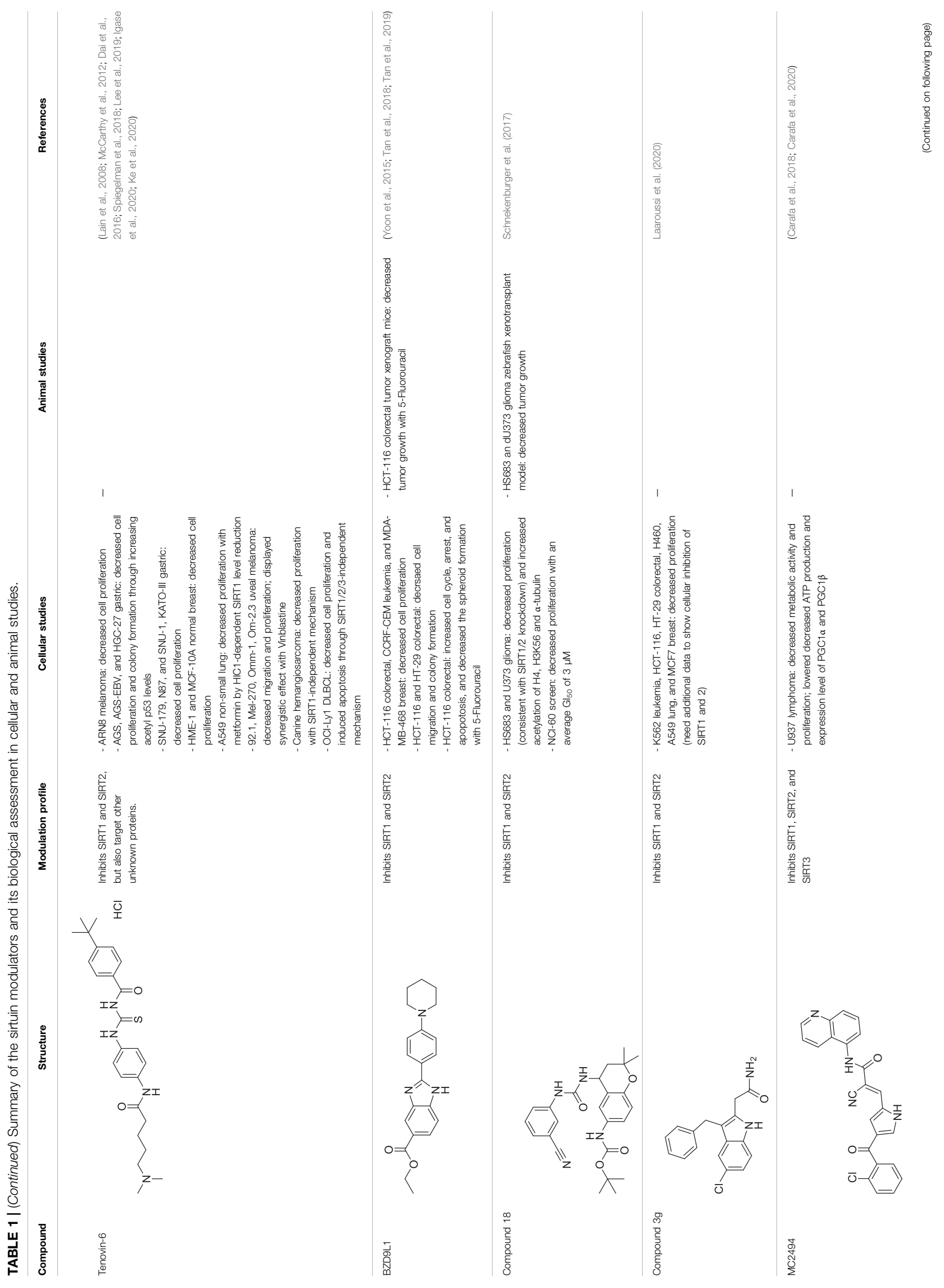




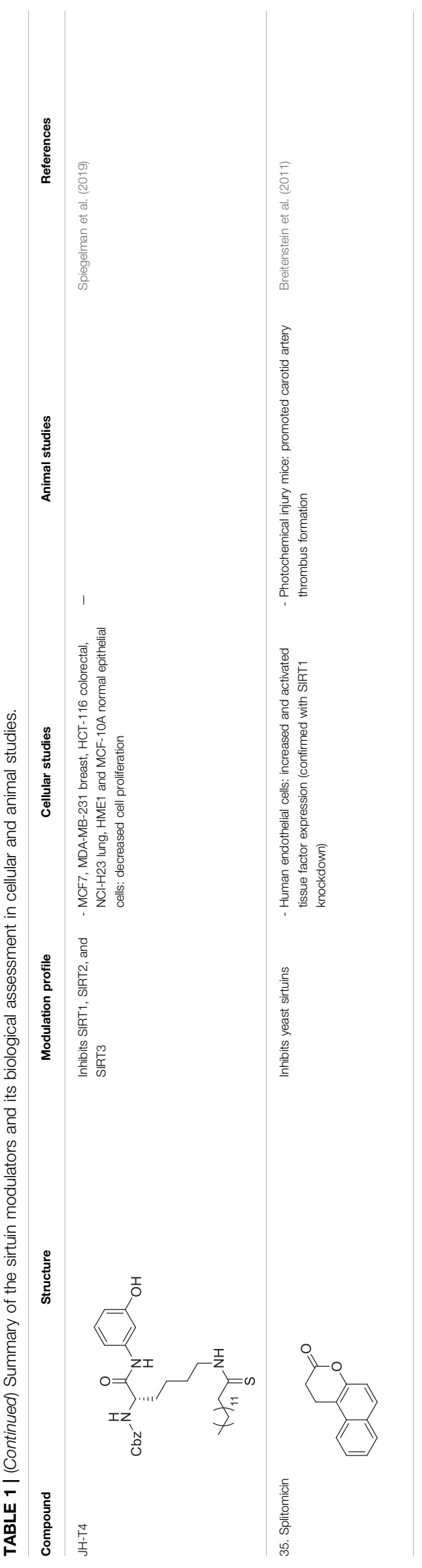

or quercetin activated sirtuins (Aksoy et al., 2006; Lee, 2006; Escande et al., 2013). Because this review specifically summarizes modulators that directly bind to sirtuins, we will not explain these indirect modulators in detail.

\section{SIRT1 Modulators}

Because SIRT1 was initially connected to longevity, many smallmolecule activators have been developed and tested for anti-aging purposes (Howitz et al., 2003; Borra et al., 2005; Milne et al., 2007). However, many follow-up studies questioned the activating mechanism, as the activation was only observed when using aminomethylcoumarin or fluorophore-tagged peptide substrate for in vitro assays (Beher et al., 2009; Pacholec et al., 2010). The original authors have rebutted this by showing direct allosteric SIRT1 activation with biochemical assays and crystallography structures (Dai et al., 2010; Hubbard et al., 2013). Later, it was found that a SIRT1 activator could also inhibit SIRT3 (Nguyen et al., 2013). Thus, the effects of SIRT1 activators may not necessarily come from the activated SIRT1. Lastly, there are already numerous review articles covering these SIRT1 activators (Hubbard and Sinclair, 2014; Dai et al., 2018; Fujita and Yamashita, 2018; Salehi et al., 2018; Iside et al., 2020). Due to these reasons, we have decided to leave out the discussion on SIRT1 activators in this review.

For SIRT1, EX-527 or selistat is the most used SIRT1 selective inhibitor in biological studies. EX-527 inhibited SIRT1 with an IC $_{50}$ of $38 \mathrm{nM}$ with 200 -fold selectivity over SIRT2 and SIRT3 (Solomon et al., 2006). When using a H3K56 fluorogenic substrate, $200 \mu \mathrm{M}$ of EX-527 showed 56\% SIRT6 inhibition (Kokkonen et al., 2014). Nevertheless, EX-527 still showed significantly stronger SIRT1 selectivity over SIRT6. In cells, EX-527 treatment significantly increased the acetylation of p53, a SIRT1 deacetylation substrate (Solomon et al., 2006). Several other SIRT1 inhibitors were reported, but whether they selectively inhibit SIRT1 was not validated (Kozako et al., 2015; Ghosh et al., 2017).

\section{SIRT2 Inhibitors}

AGK2 was synthesized from a high-throughput screening and showed SIRT2 inhibition with an $\mathrm{IC}_{50}$ of $8 \mu \mathrm{M}$ and 5 -fold selectivity for SIRT2 over SIRT1 (Outeiro et al., 2007). In cells, AGK2 significantly increased acetylation levels of a-tubulin, a SIRT2 deacetylation substrate (Mangas-Sanjuan et al., 2015; Spiegelman et al., 2018). A limitation of using AGK2 in biological studies is its poor solubility in water and ethanol. Furthermore, according to SelleckChem, its maximum solubility in DMSO is only about $23 \mathrm{mM}$ at $50^{\circ} \mathrm{C}$. The poor solubility could make it difficult to use it in cells and animals.

AK-7 inhibited SIRT2 with an $\mathrm{IC}_{50}$ of $15.5 \mu \mathrm{M}$ and does not inhibit SIRT1 or SIRT3 (Taylor et al., 2011). The main advantage of AK-7 is its brain permeability. After $2 \mathrm{~h}$ of intraperitoneal injection to mice, about $2 \mu \mathrm{M}$ of AK-7 was detected in the brain. As such, utilizing AK-7 in neurological diseases could be helpful.

SirReal2 binds a hydrophobic pocket of SIRT2, where the long-chain fatty acyl group of substrates occupies (Rumpf et al., 2015). SirReal2 inhibited SIRT2 with an $\mathrm{IC}_{50}$ of $140 \mathrm{nM}$ without any inhibition of other sirtuins. In cells, SirReal 2 led to increase in 
acetylation levels of $\alpha$-tubulin and BuBR1, acetylation targets of SIRT2. Furthermore, SirReal2 did not affect acetylation level of p53, a substrate of SIRT1 (Rumpf et al., 2015; Spiegelman et al., 2018).

From a large library screening of 140,000 compounds, RK91230156 was discovered to inhibit SIRT2 over SIRT1, SIRT3, HDAC1, and HDAC6. Moreover, RK-91230156 inhibits SIRT2 with an $\mathrm{IC}_{50}$ of $0.18 \mu \mathrm{M}$. RK-91230156 significantly increased acetylation of eIF5a, another reported SIRT2 deacetylation target (Shah et al., 2016).

NCO-90 and NCO-141 are nicotinamide-derived SIRT2 selective inhibitors with $\mathrm{IC}_{50}$ values of 1 and $0.57 \mu \mathrm{M}$, respectively. In HCT-116 colorectal cells, treatment with NCO-90 increased the acetylation level of a-tubulin, while did not affect the acetylation level of p53 (Suzuki et al., 2012). By attaching NCO-90 to a thioacylated lysine, KPM-2 was synthesized. Unlike NCO-90, KPM-2 simultaneously inhibits SIRT1, SIRT2, and SIRT3. Its IC $_{50}$ values for SIRT1, SIRT2, and SIRT3 were $1.56,0.055$, and $9.49 \mu \mathrm{M}$, respectively. In cells, KPM-2 dose-dependently increased the acetylation of a-tubulin (Mellini et al., 2017). Compound 53 is an NCO-90-based diketopiperazine compound that inhibits SIRT2 by concurrently occupying the selectivity pocket, substratebinding site, and $\mathrm{NAD}^{+}$binding site. Compound 53 inhibited SIRT2 at an IC $_{50}$ of $0.31 \mu \mathrm{M}$ with 250 and 223-fold selectivity over SIRT1 and SIRT3, respectively. In MCF7 cells, Compound 53 increased the acetylation level of a-tubulin (Mellini et al., 2019).

Discovered from high-throughput screening of RIKEN NPDepo chemical library, NPD11033 selectively inhibited SIRT2 deacetylase activity with $\mathrm{IC}_{50}$ of $0.46 \mu \mathrm{M}$, but did not inhibit SIRT2 defatty-acylase activity (Kudo et al., 2018). NPD11033 increased acetylation level of eIF5A in PANC-1 pancreatic cells (Kudo et al., 2018).

Compound $6 \mathrm{f}$ and Compound 12a are Chroman-4-one and chromone-based SIRT2 inhibitors with $\mathrm{IC}_{50}$ of 3.7 and $12.2 \mu \mathrm{M}$, respectively. They increased the acetylation level of a-tubulin in cells (Seifert et al., 2014). 1,2,4-oxadizazole-based Compound 35 and 39 inhibited SIRT2 through an uncompetitive mechanism against $\alpha$-tubulin peptide substrate and $\mathrm{NAD}^{+}$. Their SIRT2 $\mathrm{IC}_{50}$ were 10.4 and $1.5 \mu \mathrm{M}$, respectively. In NB4 and U937 cells, both Compound 35 and 39 increased acetyl $\alpha$-tubulin (Moniot et al., 2017). A SIRT2 selective inhibitor, Compound 24a was discovered from a SAR study of $\mathrm{N}$-(3-(phenoxymethyl)phenyl)acetamide derivatives (Yang et al., 2018). It binds to the hydrophobic acyl pocket and inhibits SIRT2 with an $\mathrm{IC}_{50}$ of $0.815 \mu \mathrm{M}$. Furthermore, Compound $24 \mathrm{a}$ did not inhibit other sirtuins at $100 \mu \mathrm{M}$. In H441 non-small lung cancer cells, Compound 24a increased the acetylation level of $\alpha$-tubulin (Yang et al., 2018).

As mentioned, sirtuins form a covalent O-acyl-ADP-ribose intermediate during its catalytic reaction. Many thioacyl lysine compounds (or the corresponding thiourea) form similar covalent intermediates, but the substitution of the oxygen atom by sulfur inhibits the downstream decomposition of the intermediate, which occupies the active site and inhibits sirtuins (Smith and Denu, 2007; Feldman et al., 2015; Jing et al., 2016).

TM contains a thiomyristoyl lysine with an N-terminal carboxybenzoyl $(\mathrm{Cbz})$ group and a C-terminal amide formed with aniline (Jing et al., 2016). TM selectively inhibited SIRT2 by forming a stalled covalent intermediate, which was captured by mass spectrometry. In cells, treatment of TM increased acetylation of a-tubulin in a dose-dependent manner. Moreover, its SIRT2 $\mathrm{IC}_{50}$ was $0.04 \mu \mathrm{M}$ with 650 -fold selectivity over SIRT1. TM could not inhibit SIRT3 even at $50 \mu \mathrm{M}$ (Spiegelman et al., 2018). AF8, a derivative of TM with a thiourea moiety mimicking the thioacyl group, also formed a stalled covalent intermediate to selectively inhibit SIRT2 with an $\mathrm{IC}_{50}$ of $0.061 \mu \mathrm{M}$ and 180 -fold selectivity over SIRT1. In HCT116 colorectal cancer cells, AF8 increased the acetylation of a-tubulin in a dose-dependent manner but did not change the acetylation of p53 (Farooqi et al., 2019). Two other TM derivatives, NH4-6 and NH4-13 containing a trimethylammonium moiety (Hong et al., 2021), have excellent aqueous solubility compared to TM. The difference between the two inhibitors is that NH4-6 has an amide linkage and NH4-13 has an ester linkage between the lysine and the trimethylammonium moiety. This small difference led to a completely different inhibition profile. NH4-6 with the amide bond simultaneously inhibits SIRT1, 2, and 3 with $\mathrm{IC}_{50}$ of 3, 0.032 , and $2.3 \mu \mathrm{M}$, respectively. Meanwhile, NH4-13 with the ester bond selectively inhibits SIRT2 with an $\mathrm{IC}_{50}$ of $0.087 \mu \mathrm{M}$. Furthermore, in cells, NH4-6 increased acetylation levels of p53, a-tubulin, and IDH2, acetylation targets of SIRT1, SIRT2, and SIRT3, respectively. Meanwhile, NH4-13 increased the acetylation levels of alpha-tubulin, but not of p53 and IDH2 (Hong et al., 2021).

Many reported SIRT2 inhibitors, including TM, efficiently inhibit SIRT2's deacetylase activity, but not its defatty-acylase activity. However, converting them to proteolysis-targeting chimeras (PROTAC) could enable them to inhibit both activities. TM-P4-Thal is a PROTAC SIRT2 inhibitor with thalidomide on one end and TM on the other end, connected by a polyethylene glycol (PEG) linker. The thalidomide recruits CRBN E3 ligase, while TM interacts with SIRT2. Such recruitment leads to polyubiquitination of SIRT2, thereby inducing proteolysis-mediated degradation. Degradation of SIRT2 could eradicate both SIRT2 activities in cells. As such, TM-P4-Thal had increased acetylation level of $\alpha$-tubulin and fatty acylation level of K-Ras4a, a defatty-acylation substrate of SIRT2 (Hong et al., 2020).

\section{SIRT3 Inhibitors}

Several SIRT3 inhibitors that have been reported. LC-0296 based on glutamic acid with heterocyclic rings inhibited SIRT3 with an $\mathrm{IC}_{50}$ of $3.6 \mu \mathrm{M}$ and a 10 -fold selectivity over SIRT2 (Alhazzazi et al., 2016). LC-0296 increased mitochondrial global acetylation and several SIRT3-specific deacetylation targets, including NDUFA9 and GDH (Alhazzazi et al., 2016).

YC8-02 is another mechanism-based sirtuin inhibitor based on TM, with 3-aminophenol replacing the aniline, and triphenylphosphine group replacing the $\mathrm{Cbz}$ group of $\mathrm{TM}(\mathrm{Li}$ et al., 2019). With the additional hydroxyl group of 3aminophenol, YC8-02 simultaneously inhibits SIRT1, SIRT2, and SIRT3 with $\mathrm{IC}_{50}$ of $2.8,0.062$, and $0.53 \mu \mathrm{M}$, respectively. Because SIRT3 is localized in mitochondria, the 
triphenylphosphine group, known as a mitochondrial targeting moiety, helps to direct the inhibitor to the mitochondria and thus increase SIRT3 targeting in cells. After treating DLBLC cells, YC8-02 was detected by mass spectrometry in the purified mitochondria extract, which confirms the mitochondrial targeting of YC8-02. In addition, increased global mitochondrial acetylation was observed upon treatment of YC8-02. Similar treatment with JH-T4, which also inhibits SIRT1, SIRT2, and SIRT3 in vitro but does not possess the triphenylphosphine group, did not alter the acetylation level of mitochondria.

\section{SIRT5 Inhibitors}

Several SIRT5 inhibitors have been developed, but only a few of them were tested in cellular and mice models. A dipeptide SIRT5 selective inhibitor, DK1-04 contains a lysine with thiourea moiety mimicking the glutaryl group (Abril et al., 2021). It inhibits SIRT5 by forming a covalent intermediate with $\mathrm{NAD}^{+}$. DK1-04 selectively inhibited SIRT5 with an IC50 of $0.34 \mu \mathrm{M}$. Because the carboxylic acid of DK1-04 hinders the cell permeability, DK104e, a pro-drug with an ethyl ester group on the carboxylic acid, was synthesized for biological evaluations. In cells, DK1-04e had increased mitochondrial lysine succinylation, which validates its cellular SIRT5 inhibition.

\section{SIRT6 Modulators}

Many SIRT6 activators have been recently developed and tested in cancer studies. Pyrrolo[1,2-a]quinoxaline-derived UBCS039 activated SIRT6 at $\mathrm{EC}_{50}$ of $38 \mu \mathrm{M}$ by binding to its fatty acyl pocket (You et al., 2017). UBCS039 also mildly (2-fold) activated SIRT5 at $100 \mu \mathrm{M}$, but not SIRT1, SIRT2, and SIRT3. In an in vitro SIRT6 deacetylation reaction using full-length histones or nucleosome from HeLa cells, UBCS039 significantly enhanced the deacetylation of H3K18. In H1299 non-small cell lung carcinoma cells, treatment of UBSC039 decreased acetylation of histone H3 K9 and K56, two known SIRT6 deacetylation targets (Iachettini et al., 2018).

Utilizing the Allosite server, MDL-800 was discovered to activate SIRT6 by binding a pocket around Phe83 and Phe86 residues of SIRT6. MDL-800 activated SIRT6 with an $\mathrm{EC}_{50}$ of $10.3 \mu \mathrm{M}$ and 10-fold selectivity over SIRT2, SIRT5, and SIRT7. Furthermore, MDL-800 did not activate SIRT1, SIRT3, SIRT4, or HDAC1-11. In BEL7405 hepatocellular carcinoma cells, MDL-800 decreased the acetylation level of $\mathrm{H} 3 \mathrm{~K} 9$ and $\mathrm{H} 3 \mathrm{~K} 56$, which are known SIRT6 deacetylation targets (Huang et al., 2018).

In addition to the activators, several SIRT6 selective inhibitors have been reported although they are not very potent. Quinazolinedione-based Compound 2, 3, and 8 inhibited SIRT6 at $\mathrm{IC}_{50}$ of 60,37 , and $49 \mu \mathrm{M}$, respectively. Compound 2 mildly inhibited SIRT1 and SIRT2 with IC $_{50}$ of 238 and $159 \mu \mathrm{M}$, respectively. Also, Compound 3 mildly inhibited SIRT2 with an $\mathrm{IC}_{50}$ of $85 \mu \mathrm{M}$. Compound 8 was 5 -fold selective for SIRT6 over SIRT2. Compound 3 and 8 showed 11 and 133-fold SIRT6 selectivity over SIRT1. In BxPC-3 pancreatic cells, treatment of Compound 2, 3, and 8 increased acetylation of H3K9 (Sociali et al., 2015).
Salicylate-based OSS-128167 inhibited SIRT6 with an $\mathrm{IC}_{50}$ of $89 \mu \mathrm{M}$ and 17 and 8 -fold selectivity over SIRT1 and SIRT2, respectively. In BxPC-3 pancreatic cells, OSS-128167 increased the acetylation level of $\mathrm{H} 3 \mathrm{~K} 9$ and glucose uptake, and decreased TNF- a secretion. Similar effects were also observed when SIRT6 was knocked down (Parenti et al., 2014). Later, Compound 5 and 11 were designed to have stronger potency than OSS-128167. These inhibitors had inhibited SIRT6 with IC $_{50}$ of 34 and $22 \mu \mathrm{M}$ by binding to the nicotinamide and substrate pocket. Furthermore, both inhibitors showed 14-fold selective SIRT6 inhibition over SIRT1 and SIRT2. In BxPC-3 pancreatic cells, Compound 5 and 11 increased the acetylation level of $\mathrm{H} 3 \mathrm{~K} 9$ (Damonte et al., 2017). In this same study, Compound 1 was also reported to inhibit SIRT6 with an $\mathrm{IC}_{50}$ of $106 \mu \mathrm{M}$. Additionally, Compound 1 inhibited SIRT2 at an $\mathrm{IC}_{50}$ of $114 \mu \mathrm{M}$ (Damonte et al., 2017). Although Compound 1 inhibited both SIRT2 and SIRT6, Compound 1 had the most suitable physicochemical properties for the in vivo studies, as it had moderate oral absorption, aqueous solubility, and metabolic stability (Sociali et al., 2017).

\section{Pan-Sirtuin Inhibitors}

Because sirtuins share similar structures, many modulators simultaneously interact with multiple sirtuins.

Identified in 2006, Cambinol moderately inhibits SIRT1 and SIRT2 through competitive inhibition against histone $\mathrm{H} 4$ and noncompetitive inhibition against $\mathrm{NAD}^{+}$. Cambinol inhibited SIRT1 and SIRT2 at IC $_{50}$ of 56 and $59 \mu \mathrm{M}$, respectively. In NCI H460 cells, treatment of Cambinol had significantly increased acetylation of p53 and a-tubulin (Heltweg et al., 2006).

Through high-throughput screening and optimization, Sirtinol was identified as a SIRT1 and SIRT2 inhibitor, with $\mathrm{IC}_{50}$ of 131 and $58 \mu \mathrm{M}$, respectively (Grozinger et al., 2001; Mai et al., 2005). However, it failed to increase global acetylation levels of histone and a-tubulin in cells (Grozinger et al., 2001). Salermide contains a reversed amide structure of sirtinol and shows mild SIRT1 and SIRT2 inhibitions. Salermide showed $80 \%$ inhibition of SIRT1 and SIRT2 at 100 and $25 \mu \mathrm{M}$, respectively. Only in some specific cell lines, Salermide treatment increased the acetylation of $\alpha$-tubulin and p53. Also, it did not affect global H4 acetylation levels, a previously reported SIRT2 substrate (Lara et al., 2009). Thus, when using Sirtinol and Salermide, additional confirmation will be needed to verify whether the observed effects are due to the sirtuin inhibition.

From screening compounds for p53 activation, Tenovin- 6 was discovered to simultaneously inhibit SIRT1 and SIRT2 with $\mathrm{IC}_{50}$ of 26 and $9 \mu \mathrm{M}$, respectively (Lain et al., 2008; McCarthy et al., 2012). In ARN8 melanoma cells, Tenovin-6 increased the acetylation level of p53 and $a$-tubulin. The increase of acetylation level of $\alpha$-tubulin by Tenovin- 6 was rescued with SIRT2 overexpression (Lain et al., 2008). Despite its effective SIRT1 and SIRT2 inhibition, Tenovin-6 may target other proteins in cells. For instance, Tenovin- 6 impaired cellular growth of canine hemangiosarcoma cells through a SIRT1independent mechanism (Igase et al., 2020). Tenovin-6's effect in DLBCL cells is also thought to be SIRT1/2/3 
TABLE 2 | Cell lines affected by SIRT1 Inhibitors.

\begin{tabular}{|c|c|c|}
\hline \multirow[t]{2}{*}{ Type } & \multirow[t]{2}{*}{ Line } & SIRT1 Inhibitor \\
\hline & & EX-527 \\
\hline \multirow[t]{2}{*}{ Glioma } & U87MG & $\downarrow$ proliferation \\
\hline & LN0299 & $\downarrow$ proliferation \\
\hline \multirow[t]{2}{*}{ Bladder } & 5637 & $\downarrow$ proliferation \\
\hline & $\mathrm{T} 24$ & $\downarrow$ proliferation \\
\hline \multirow[t]{3}{*}{ Lung } & H-460-R- cisplatin resistant & $\uparrow$ senstivity to cisplatin \\
\hline & A549 & $\uparrow$ senstivity with MK-1775 \\
\hline & A549 (xenograft) & $\downarrow$ tumor growth with MK-1775 \\
\hline \multirow[t]{4}{*}{ Endometrial carcinoma } & HEC151 & $\downarrow$ proliferation \\
\hline & HEC1B & $\downarrow$ proliferation \\
\hline & HHUA & $\downarrow$ proliferation \\
\hline & HHUA (xenograft) & $\downarrow$ tumor growth \\
\hline Prostate & PC-3 & $\uparrow$ senstivity to vesicular stomatitis virus oncolysis \\
\hline \multirow[t]{2}{*}{ Pancreatic } & PANC-1 & $\downarrow$ proliferation $\uparrow$ senstivitiy to gemcitabine \\
\hline & PANC-1 (xenograft) & $\uparrow$ tumor growth \\
\hline Lymphoma & Chemo-resistant K562 & $\uparrow$ sensitivity to $17-A A G$ and AUY922 \\
\hline
\end{tabular}

independent (Yuan et al., 2017). Another drawback of Tenovin6 was its over-toxicity. In a direct comparative study with other SIRT2 inhibitors, even though Tenovin- 6 showed the strongest antiproliferative effect, it also killed tested normal epithelial cell lines (Spiegelman et al., 2018). Thus, when using Tenovin-6 in vitro or in vivo, extra care is need to rule out off-target effect and avoid toxicity issues.

BZD9L1, a highly fluorescent sirtuin inhibitor, inhibited SIRT1 and SIRT2 with $\mathrm{IC}_{50}$ of 42.9 and $9 \mu \mathrm{M}$, respectively. Based on the docking study with SIRT2, BZD9L1 occupied where adenosine diphosphate ribose bound. In HCT-116 colorectal cells, BZD9L1 increased acetylation of p53 after etoposide-induced DNA damage and $\alpha$-tubulin. Because BZD9L1 possesses intrinsic fluorescence, the cellular distribution of BZD9L1 in HCT-116 and CCD18 colon fibroblasts could be detected using fluorescence microscopy (Yoon et al., 2015).

$\mathrm{N}$-aryl-N'-3,4-dihydro-2,2-dimethyl-2H-1-benzopyran-4-yl) ureas-derived Compound 18 simultaneously inhibited SIRT1 and SIRT2 with $\mathrm{IC}_{50}$ of 6.2 and 4.2 , respectively (Schnekenburger et al., 2017). In U373 and Hs683 glioblastoma, treatment of Compound 18 increased acetylation of histone $\mathrm{H} 4$ and a-tubulin (Schnekenburger et al., 2017).

Compound $3 \mathrm{~g}$, an achiral indole analog of EX-527, showed potent inhibition against both SIRT1 and SIRT2 with IC $_{50}$ of 4.9 and $1(0.62-1.4) \mu \mathrm{M}$, respectively (Laaroussi et al., 2020).

MC2494 inhibited all SIRT1-6 with $\mathrm{IC}_{50}$ values of 38.5 and $58.6 \mu \mathrm{M}$ for SIRT1 and SIRT2. Upon thermal stress, MC2494 protected SIRT1, SIRT2 and SIRT3 against degradation. In cells, MC2494 increased not only the global lysine acetylation but also acetylation levels of p53, tubulin, histone H3, and histone H4 (Carafa et al., 2018).

JH-T4 is an analog of TM with a 3-aminophenol group replacing the aniline part of TM (Spiegelman et al., 2019).
Interestingly, with just one additional hydroxyl group, JH-T4 inhibits SIRT1, SIRT2, and SIRT3. From the docking study with SIRT2, the hydroxyl group forms a hydrogen bond interaction with the protein backbone of the sirtuins, which could have contributed to its simultaneous inhibition. Moreover, JH-T4 inhibits both SIRT2 deacetylase and defatty-acylase, as increased acetylation of a-tubulin and fatty-acylation of K-Ras4a were observed upon treatment of JH-T4 (Spiegelman et al., 2019).

\section{SIRTUIN MODULATORS IN CANCER}

Because sirtuins are involved in a plethora of biological pathways, they could play both tumor suppressor and activator roles (Bosch-Presegue and Vaquero, 2011; Hu et al., 2014). In this section, we will briefly highlight the roles of sirtuins and their modulators in tumorigenesis.

\section{SIRT1 Inhibitors in Cancer}

SIRT1 could serve as a tumor suppressor as it deacetylates and inactivates various tumor-promoting transcriptional factors. For instance, SIRT1 deacetylates K310 of NF- $\mathrm{KB}$ and attenuates its transcriptional activity, which consequently suppress inflammation and turmorigenesis (Chen et al., 2002; Yeung et al., 2004). This promotes TNF-a induced apoptosis. Also, SIRT1 deacetylates and inactivates HIF-1 $\alpha$, which leads to repression of HIF-1a target genes. In mice, xenografted HT1080 tumors with SIRT1 overexpression formed smaller tumors than the xenografted wild-type HT1080 tumors (Lim et al., 2010). Knockdown of SIRT1 in HMLER breast cancer cells increased metastasis. In the same study, SIRT1 was reported to deacetylate $\operatorname{Smad} 4$ and subsequently keep $\beta$-catenin interacting with E-adherin. 
TABLE 3 | Cell lines affected by SIRT2 Inhibitors (\#1 set).

\begin{tabular}{|c|c|c|c|c|c|c|c|c|}
\hline \multirow[t]{2}{*}{ Type } & \multirow[t]{2}{*}{ Line } & \multicolumn{7}{|c|}{ SIRT2 Inhibitor } \\
\hline & & AGK2 & AK7 & SirReal2 & RK-91230156 & NCO-90/141 & NPD11033 & $\begin{array}{c}\text { Compound } \\
6 f / 12 a\end{array}$ \\
\hline \multirow[t]{5}{*}{ Glioma } & GB2 & $\downarrow$ proliferation & - & - & - & - & - & - \\
\hline & GB2 (xenograft) & - & $\downarrow$ tumor growth & - & - & - & - & - \\
\hline & GB3 & $\downarrow$ proliferation & - & - & - & - & - & - \\
\hline & GB11 & $\downarrow$ proliferation & - & - & - & - & - & - \\
\hline & GB16 & $\downarrow$ proliferation & - & - & - & - & - & - \\
\hline \multirow[t]{2}{*}{ Lung } & A549 & - & - & $\downarrow$ proliferation & - & - & - & $\downarrow$ proliferation \\
\hline & H520 & - & - & $\downarrow$ proliferation & - & - & - & - \\
\hline Pancreatic & PANC-1 & - & - & - & - & - & $\begin{array}{l}\downarrow \\
\text { proliferation }\end{array}$ & - \\
\hline \multirow[t]{3}{*}{ Colorectal } & НCT-116 & $\begin{array}{l}\downarrow \text { effect of } \\
\text { chemotherapeutic } \\
\text { agents }\end{array}$ & - & $\downarrow$ proliferation & - & - & - & - \\
\hline & SW620 & $\begin{array}{l}\uparrow \text { effect of } \\
\text { chemotherapeutic } \\
\text { agents }\end{array}$ & - & - & - & - & - & - \\
\hline & SW948 & - & - & $\downarrow$ proliferation & - & - & - & - \\
\hline \multirow[t]{4}{*}{ Leukemia } & $\mathrm{S} 1 \mathrm{~T}$ & - & - & - & - & $\begin{array}{l}\uparrow \text { acetylation } \\
\text { of } \mathrm{H} 4\end{array}$ & - & - \\
\hline & MT-2 & - & - & - & - & $\begin{array}{l}\uparrow \text { acetylation } \\
\text { of } \mathrm{H} 4\end{array}$ & - & - \\
\hline & Jurkat & - & - & - & - & $\begin{array}{l}\uparrow \text { acetylation } \\
\text { of } \mathrm{H} 4\end{array}$ & - & - \\
\hline & HL60 & - & - & - & - & $\begin{array}{l}\uparrow \text { acetylation } \\
\text { of } \mathrm{H} 4\end{array}$ & - & - \\
\hline \multirow[t]{2}{*}{ Lymphoma } & $\begin{array}{l}\text { Chemo-resistant } \\
\text { K562 }\end{array}$ & - & - & $\downarrow$ proliferation & - & - & - & - \\
\hline & K562 & - & - & $\downarrow$ proliferation & - & - & - & - \\
\hline \multirow[t]{2}{*}{ Gastric } & HGC-27 & - & - & $\downarrow$ proliferation & - & - & - & - \\
\hline & MGC-803 & - & - & $\downarrow$ proliferation & - & - & - & - \\
\hline \multirow[t]{3}{*}{ Breast } & MCF7 & - & - & $\downarrow$ proliferation & $\downarrow$ proliferation & - & - & $\downarrow$ proliferation \\
\hline & MDA-MB-231 & - & - & $\downarrow$ proliferation & - & - & - & - \\
\hline & MDA-MB-468 & - & - & $\downarrow$ proliferation & - & - & - & - \\
\hline Cervical & HeLa & - & - & $\downarrow$ proliferation & - & - & - & - \\
\hline
\end{tabular}

This would suppress the epithelial-to-mesenchymal transition (Simic et al., 2013).

In contrast, some studies reported SIRT1 as a tumor activator. SIRT1 deacetylates FOXO1 and inhibits FOXO1-induced apoptosis (Yang et al., 2005). SIRT1 overexpression increases the expression of c-Myc, a key oncoprotein that increases the expression of many tumor proliferating genes. Furthermore, SIRT1 deacetylates c-Myc to promote its transcriptional activity (Menssen et al., 2012). SIRT1 deacetylates and represses p53, which exerts antiproliferative effects, including growth arrest, apoptosis, and cell senescence. Deacetylation of p53 also translocates p53 to mitochondria, which suppresses its transcriptional activity (Han et al., 2008). In MCF7 breast cancer cells, overexpression of SIRT1 increased the proliferation, migration, and motility by increasing the POLD1 expression (Xu et al., 2018). The dual role of SIRT1 is also depicted in HCT-116 colorectal cells. Heterozygous deletion of SIRT1 increased c-Myc expression, and thereby promoted tumor growth. Meanwhile, homozygous deletion of SIRT1 promoted apoptosis and delayed cancer formation (Ren et al., 2017). Thus, the role of SIRT1 in cancer may vary depending on the context.

There are only a few reports of EX-527 producing effective anticancer effects as a single agent (see summary in Table 2). In U87MG and LN-299 glioma cells, EX-527 decreased the cellular proliferation and anchorage-independent colony formation through p53 and acetylated-p53 upregulation, and caspasedependent apoptosis activation (Wang et al., 2020). In 5637 and T24 bladder cancer cells, SIRT1 overexpression promoted cell proliferation and GLUT1 expression. Hence, treatment of EX-527 in these cells had an opposite effect, which decreased the proliferation, glycolysis, and glucose uptake (Chen et al., 2019).

In contrast, many reports indicate that EX-527 can enhance and synergize with other treatments. For instance, by inhibiting the deacetylation of XRCC1, EX-527 increased sensitivity of 
TABLE 4 | Cell lines affected by SIRT2 Inhibitors (\#2 set).

\begin{tabular}{|c|c|c|c|c|c|c|c|c|c|}
\hline \multirow[t]{2}{*}{ Type } & \multirow[t]{2}{*}{ Line } & \multicolumn{8}{|c|}{ SIRT2 Inhibitor } \\
\hline & & $\begin{array}{c}\text { Compound } \\
35\end{array}$ & $\begin{array}{c}\text { Compound } \\
39\end{array}$ & Compound 24a & Compound 53 & TM & AF8 & NH4-13 & TM-P4-Thal \\
\hline Various & $\mathrm{NCl}-60$ & - & - & - & - & $\downarrow$ proliferation & - & - & - \\
\hline \multirow[t]{4}{*}{ Glioma } & U87MG & - & - & - & - & - & - & $\downarrow$ proliferation & - \\
\hline & Lung & A549 & - & - & - & - & - & $\downarrow$ proliferation & $\downarrow$ proliferation \\
\hline & & $\mathrm{NCl}-\mathrm{H} 23$ & - & - & - & - & - & - & $\downarrow$ proliferation \\
\hline & $\begin{array}{l}\text { Non-small } \\
\text { Lung }\end{array}$ & $\mathrm{H} 441$ & - & - & $\downarrow$ proliferation & - & - & - & - \\
\hline \multirow[t]{2}{*}{ Pancreatic } & $\mathrm{BxPC}-3$ & - & - & - & - & - & $\begin{array}{l}\downarrow \\
\text { proliferation }\end{array}$ & - & - \\
\hline & $\begin{array}{l}\text { Mia- } \\
\text { PaCa-2 }\end{array}$ & - & - & - & - & - & - & $\downarrow$ proliferation & - \\
\hline \multirow[t]{3}{*}{ Colorectal } & HCT-116 & - & - & - & - & - & $\begin{array}{l}\downarrow \\
\text { proliferation }\end{array}$ & $\downarrow$ proliferation & - \\
\hline & $\begin{array}{l}\text { HCT-116 } \\
\text { (xenograft) }\end{array}$ & - & - & - & - & - & $\begin{array}{l}\downarrow \text { tumor } \\
\text { growth }\end{array}$ & $\downarrow$ tumor growth & - \\
\hline & SW948 & - & - & - & - & - & $\downarrow$ & $\downarrow$ proliferation & - \\
\hline \multirow[t]{2}{*}{ Leukemia } & HL60 & - & $\downarrow$ proliferation & - & - & - & - & - & - \\
\hline & NB4 & $\downarrow$ proliferation & $\downarrow$ proliferation & - & - & - & - & - & - \\
\hline \multirow[t]{8}{*}{ Lymphoma } & K562 & $\downarrow$ proliferation & - & - & - & - & - & - & - \\
\hline & Karpas299 & $\downarrow$ proliferation & $\downarrow$ proliferation & - & - & - & - & - & - \\
\hline & U937 & - & $\downarrow$ proliferation & - & - & - & - & - & - \\
\hline & OCI-AML3 & - & - & - & - & - & - & - & - \\
\hline & IMS-M2 & - & $\downarrow$ proliferation & - & - & - & - & - & - \\
\hline & OCl-AML3 & - & $\downarrow$ proliferation & - & - & - & - & - & - \\
\hline & MV4-11 & - & $\downarrow$ proliferation & - & - & - & - & - & - \\
\hline & Kasumi1 & - & $\downarrow$ proliferation & - & - & - & - & - & - \\
\hline \multirow[t]{4}{*}{ Breast } & MCF7 & - & - & - & $\downarrow$ proliferation & $\downarrow$ proliferation & $\begin{array}{l}\downarrow \\
\text { proliferation }\end{array}$ & $\downarrow$ proliferation & $\downarrow$ proliferation \\
\hline & $\begin{array}{l}\text { MDA- } \\
\text { MB-231 }\end{array}$ & $\downarrow$ proliferation & - & - & - & $\downarrow$ proliferation & $\begin{array}{l}\downarrow \\
\text { proliferation }\end{array}$ & $\downarrow$ proliferation & $\downarrow$ proliferation \\
\hline & $\begin{array}{l}\text { MDA-MB- } \\
231 \\
\text { (xenograft) }\end{array}$ & - & - & - & - & $\downarrow$ tumor growth & - & - & - \\
\hline & $\begin{array}{l}\text { MDA- } \\
\text { MB-468 }\end{array}$ & - & - & - & - & $\downarrow$ proliferation & $\begin{array}{l}\downarrow \\
\text { proliferation }\end{array}$ & - & - \\
\hline Cervical & HeLa & - & - & - & - & - & - & $\downarrow$ proliferation & - \\
\hline Normal & MCF-10A & - & - & - & - & No effect & - & - & - \\
\hline Epithelial & HME1 & - & - & - & - & No effect & - & - & - \\
\hline
\end{tabular}

H460-R cisplatin-resistant lung cancer cells to cisplatin. Overexpression of SIRT1 rescued such effect, while the knockdown of SIRT1 also made cells vulnerable to cisplatin (Yousafzai et al., 2019). In addition, EX-527 impaired the proliferation of several cisplatin-resistant endometrial carcinoma cells, such as HEC151, HEC1B, and HHUA. In HHUA cells, overexpression of SIRT1 reversed enhanced cisplatin resistance. In the HHUA tumor xenograft mice model, treatment with EX-527 significantly detained the tumor growth (Asaka et al., 2015). In PC-3 prostate cancer, SIRT1 knockdown or EX-527 increased the effect of vesicular stomatitis virus oncolysis treatment (Muscolini et al., 2019). In chemo-resistant stem-like cells from leukemia K562, EX-527 or SIRT1 knockdown increased the effect of Hsp90 inhibitors like
17-AAG and AUY922. SIRT1 inhibition or depletion decreased expression of heat shock proteins, and consequently increased the effects of Hsp90 inhibitors (Kim et al., 2015). EX-527 and SIRT1 knockdown also induced a synergistic anticancer effect with MK1775, a WEE1 inhibitor. In both cellular and xenograft mice models, treatment of EX-527 and MK-1775 suppressed the growth of A549 lung cancer cells. Meanwhile, a single treatment of EX-527 or MK-1775 did not affect the growth. Mechanistically, SIRT1 can deacetylate and inhibit NBS1 and Rad51 in homologous recombination repair. Thus, the combination of EX-527 and MK-1775 induced complete damage in the DNA replication process (Chen et al., 2017). Lastly, in PANC-1 pancreatic cancer cells, EX-527 itself decreased proliferation, and synergistically increased the 
TABLE 5 | Cell lines affected by SIRT3/SIRT5 inhibitors.

\begin{tabular}{|c|c|c|c|c|}
\hline \multirow[t]{2}{*}{ Type } & \multirow[t]{2}{*}{ Line } & \multicolumn{2}{|c|}{ SIRT3 Inhibitor } & \multirow{2}{*}{$\frac{\text { SIRT5 Inhibitor }}{\text { DK1-04e }}$} \\
\hline & & LC-0296 & YC8-02 & \\
\hline \multirow[t]{8}{*}{ Lymphoma } & OCL-LY-1 & - & $\downarrow$ proliferation & - \\
\hline & Karpas422 & - & $\downarrow$ proliferation & - \\
\hline & Karpas422 (xenograft) & - & $\downarrow$ tumor growth & - \\
\hline & HBL1 & - & $\downarrow$ proliferation & - \\
\hline & Pfeiffer & - & $\downarrow$ proliferation & - \\
\hline & SU-DHL4 & - & $\downarrow$ proliferation & - \\
\hline & TMD3 & - & $\downarrow$ proliferation & - \\
\hline & OCL-LY7 & - & $\downarrow$ proliferation & - \\
\hline \multirow[t]{3}{*}{ Breast } & MCF7 & - & - & $\downarrow$ proliferation \\
\hline & MDA-MB-231 & - & - & $\downarrow$ proliferation \\
\hline & MDA-MB-231 (xenograft) & - & - & $\downarrow$ tumor growth \\
\hline \multirow[t]{2}{*}{ HNSCC } & UM-SCC-1 & $\downarrow$ proliferation & - & - \\
\hline & UM-SCC-17B & $\downarrow$ proliferation & - & - \\
\hline
\end{tabular}

TABLE 6 | Cell lines affected by SIRT6 modulators.

\begin{tabular}{|c|c|c|c|c|c|c|c|c|}
\hline \multirow[t]{2}{*}{ Type } & \multirow[t]{2}{*}{ Line } & \multicolumn{2}{|c|}{ SIRT6 Activator } & \multicolumn{5}{|c|}{ SIRT6 Inhibitor } \\
\hline & & UBCS039 & MDL-800 & Compound 2 & Compound 3 & Compound 8 & Compound 5 & Compound 11 \\
\hline $\mathrm{NCl}-60$ & $\mathrm{NCl}-60$ & - & $\downarrow$ proliferation & - & - & - & - & - \\
\hline Non-small Lung & H1299 & $\downarrow$ proliferation & - & - & - & - & - & - \\
\hline $\begin{array}{l}\text { Hepatocellular } \\
\text { carcinoma }\end{array}$ & Bel7405 & - & $\downarrow$ proliferation & - & - & - & - & - \\
\hline Pancreatic & $\mathrm{BxPC}-3$ & - & - & $\begin{array}{l}\uparrow \text { senstivity to } \\
\text { gemcitabine }\end{array}$ & $\begin{array}{l}\uparrow \text { senstivity to } \\
\text { gemcitabine }\end{array}$ & $\downarrow$ proliferation & $\begin{array}{l}\uparrow \text { senstivity to } \\
\text { gemcitabine }\end{array}$ & $\begin{array}{l}\uparrow \text { senstivity to } \\
\text { gemcitabine }\end{array}$ \\
\hline
\end{tabular}

antiproliferative effect of gemcitabine. However, in PANC-1 tumor xenograft mice, EX-527 promoted tumor growth and did not show any additive or synergistic effect with gemcitabine (Oon et al., 2015).

Based on all the data, it is likely that SIRT1's major role is to help cells survive various stresses. Depending on the nature and level of the stresses in specific cancer cells, inhibiting SIRT1 may produce pro-tumor or anti-tumor activity. This could also explain why SIRT1 inhibition can synergize with other small molecules.

\section{SIRT2 Inhibitors in Cancer}

Although SIRT2 was initially reported to be a tumor suppressor, as Sirt2 knockout mice developed more tumors than wild-type mice as they age (Kim et al., 2011). However, this effect is relatively weak as the mice only developed tumors when they reach about 1 year old. Also, this observation could depend on the strain, as another study did not observe this phenotype (Serrano et al., 2013). More evidence links SIRT2 as a tumor activator. SIRT2 deacetylates and stabilizes several oncoproteins. SIRT2 deacetylates and promotes KRAS activity, thereby inducing cell proliferation, colony formation, and tumor growth (Yang et al., 2013). Also, SIRT2 deacetylates K116 of Slug, which subsequently stimulates the growth of basal-like breast cancer (Zhou et al., 2016). In addition, SIRT2-induced c-Myc stabilization promotes pancreatic cancer cell proliferation (Liu et al., 2013). SIRT2 deacetylates and activates $\mathrm{LDH}-\mathrm{A}$, which is responsible for lactate production in cancer cell growth (Zhao et al., 2013). In addition, SIRT2 interrupts FOXO1's interaction with ATG7 and inhibits apoptosis (Zhao et al., 2010). Through removal of longchain fatty acyl groups on lysine, SIRT2 regulates K-Ras4a transformation activity and promotes ERK via ARF6 (Jing et al., 2017; Kosciuk et al., 2020). With more reports highlighting SIRT2 as a tumor activator, numerous SIRT2 inhibitors have been developed and evaluated in cancer models (Table 3 and Table 4).

The earliest SIRT2 selective inhibitors, AGK2 was developed from high-throughput screening of a small-molecule library (Outeiro et al., 2007). Even though AGK2 treatment showed promising therapeutic effect in cancer studies, its poor aqueous solubility could be problematic to assess its full potency. According to SelleckChem, AGK2 cannot be dissolved in water and ethanol, and only can be dissolved in DMSO with $50^{\circ} \mathrm{C}$ water bath. Nevertheless, consistent with the SIRT2 knockdown results, AGK2 treatment inhibited the colony formation and induced apoptosis in GB2, GB4, GB11, and GB16 primary glioblastoma cells. In SIRT2 knockdown GB2 cells, AGK2 did not show any antiproliferative effect, which further confirms the SIRT2 selective inhibition of AGK2 in cells (Funato et al., 2018). Due to the toxicity and impermeable blood-brain barrier characteristics of AGK2, another SIRT2 inhibitor, AK7 was tested in GB2 tumor xenograft mice models. After intraperitoneal injection of AK7, a significant impediment of tumor growth was observed. Mice with transplants of 
GB2 and GB16 SIRT2 knockout cells survived longer and showed less tumorigenicity than mice with transplants GB2 and GB16 SIRT2 wild-type cells. This further confirmed that antitumor effect of AK-7 in this study was through SIRT2 perturbation (Funato et al., 2018). In HCT-116 colorectal cancer cells with wild-type TP53 expression, AGK2 treatment decreased the effects of several chemotherapeutic drugs, including cisplatin, 5fluorouracil, oxaliplatin, gefitinib, LY294002, and metformin. However, in SW620 colorectal cancer cells with mutant TP53 expression, AGK2 treatment enhanced the anticancer effects of these chemotherapeutic drugs (Yang et al., 2020).

SirReal2 was also shown to effectively decrease the growth of lung, colorectal, lymphoma, gastric, breast, and cervical cancers. SirReal 2 decreased the migration and invasion of HGC-27 and MGC-803 gastric cancer cells. SirReal2 inhibited SIRT2 from deacetylating PEPCK1, which promoted degradation of PEPCK1 and decreased mitochondrial metabolism. As a result, the migration of gastric cells was impaired. HGC-27 and MGC803 with SIRT2 knockdown showed less invasion activities, consistent with the inhibition results. Also, xenograft of SIRT2 knockdown gastric cancer cells in mice formed less metastatic tumors and showed slower growth than that of SIRT2 wild type cells (Li et al., 2018). In a comparison study of SIRT2 inhibitors, SirReal2 showed antiproliferative effects in breast, colorectal, lung, lymphoma, and cervical cancer cells (Spiegelman et al., 2018).

In MCF7 breast cancer cells, the treatment of RK-9123016 increased the acetylated eIF5a level and hindered cell proliferation through degradation of c-Myc (Shah et al., 2016).

Inhibitors with nicotinamide-core impaired proliferation of leukemia and breast cancer cells. NCO-90 and NCO-141 induced apoptosis and mitochondrial superoxide level in leukemic cells, such as HTLV-1-transformed T-cells (Kozako et al., 2018). In S1T, MT-2, Jurkat, and HL60 leukemia cells, NCO-90 and NCO-141 increased acetylation of histone H4, a previously reported SIRT2 substrate, but did not alter acetylation of p53 (Kozako et al., 2018). This confirmed that these compounds inhibited SIRT2, but not SIRT1, in cells. In addition, the treatment of NCO-90 and NCO-141 increased LCII expression level and autophagosome, which could have induced autophagic cell death (Kozako et al., 2018). KPM-2, a pan SIRT1-3 inhibitor designed from NCO-90, impaired proliferation of MDA-MB-231 breast cancer cells. In the same study, Compound 9, an inhibitor with a similar structure as KPM-2 which shows 11-fold SIRT1 selective inhibition over SIRT2 did not show any antiproliferative effect. Also, Compound 6, a weaker SIRT2 selective inhibitor with a similar structure as KPM-2 showed weaker cytotoxicity than KPM-2. Overall, both results confirmed that the cytotoxicity of KPM-2 is strongly correlated to its SIRT2 inhibition (Mellini et al., 2017).

In PANC-1 pancreatic cancer cells, NPD11033 not only decreased cell proliferation but also increased the acetylation level of eIF5a, a SIRT2 deacetylation substrate (Kudo et al., 2018). Knockdown of SIRT2 in PANC-1 cells also decreased cell proliferation. In addition, an inactive analog RK-0310020 did not show any antiproliferative effect in PANC-1 cells, which further supports that SIRT2 inhibition by NDP11033 induces its anticancer effect (Kudo et al., 2018).

Chroman-4-one and chromone-based Compound $6 \mathrm{f}$ and 12a impaired cellular proliferation of MCF7 breast cancer and A549 lung cancer cells. In addition, treatment of Compound 12a in these two cell lines led to cell cycle arrest in G1/G0 phase. Treatment of Compound $6 \mathrm{f}$ also showed similar results, but to a smaller extent. In MCF7 cells, both Compound $6 \mathrm{f}$ and 12a had increased acetylation level of a-tubulin, a SIRT2 deacetylation target (Seifert et al., 2014).

Compound 35 induced apoptosis in NB4, K562, and MDA-MB231 cancer cells, and decreased cell proliferation of NB4, Karpas299, and MV4-11 cells (Moniot et al., 2017). Moreover, Compound 39 showed a broader anticancer effect in U937, HL-60, NB4, OCIAML3, IMS-M2, OCI-AML2, MV4-11, Kasumi-1, and Karpass299 cells (Moniot et al., 2017).

In H441 non-small lung cancer cells, treatment of Compound $24 \mathrm{a}$ increased the acetylation level of $\alpha$-tubulin, and decreased cell proliferation and migration (Yang et al., 2018).

The mechanism-based SIRT2 inhibitors also demonstrated strong anti-cancer effects in cellular and animal models. A mechanism-based SIRT2 inhibitor, TM showed broad anticancer effect in most of the NCI-60 cancer cell lines. These affected cancer cell types include leukemia, non-small lung cancer, colorectal, melanoma, ovarian, renal, prostate, breast, and brain cancer cells. SIRT2 knockdown in MCF7, MDA-MB-468, and MDA-MB-231 breast cancer cells reduced the cell proliferation, confirming that SIRT2 inhibition or perturbation induces cytotoxicity. Interestingly, the control compound, $\mathrm{M}$, which differs from TM just by one atom and could not inhibit SIRT2, does not have anticancer activity. These evidences further confirm that the anticancer activity is through SIRT2 inhibition. The anticancer effect of TM is at least partially through the promotion of c-Myc degradation and SIRT2 knockdown also induced degradation of c-Myc in MCF7 cells. The treatment of TM did not impede the cellular proliferation of MCF-10A and HME1, normal breast epithelial cells. This suggests that TM treatment selectively impacts cancer cell proliferation. The intraperitoneal injection of TM significantly delayed breast tumor growths in MDA-MB-231 xenograft and genetic MMTV-PyMT mouse models without significant weight loss or other obvious toxicity (Jing et al., 2016).

A derivative of TM, AF8 also showed a broad anticancer effect in breast, pancreatic, lung, and colorectal cancer cells. AF8 inhibited the 3D anchorage-independent colony formation of HCT-116 colorectal cancer cells. Furthermore, treatment of AF8 significantly reduced the tumor growth of HCT-116 tumor xenograft mice models in a dose-dependent manner (Farooqi et al., 2019).

A direct comparison of NH4-6, which inhibits SIRT1-3, and NH4-13, which only inhibits SIRT2, showed that selective SIRT2 inhibition could be advantageous when treating cancer. In breast, colorectal, cervical, lung, pancreatic, and glioblastoma cancer cells, low concentrations of NH4-6 and NH4-13 showed weaker cytotoxicity than TM, most likely due to their poor permeability from the charged trimethylammonium moiety. However, in these cancer cells, 
higher concentrations of both inhibitors showed stronger cytotoxicity than TM, due to their improved aqueous solubility overriding their poor permeability. Furthermore, NH4-6 hindered the cellular proliferation of these cancer cells slightly more potent than NH4-13. In HCT-116 colorectal tumor xenograft mice model, daily treatment of $50 \mathrm{mg} / \mathrm{kg}$ NH4-6 caused severe toxicity, while the same dosage of NH4-13 did not alter the overall health. Furthermore, $30 \mathrm{mg} / \mathrm{kg}$ every other day injection of NH4-6 and NH4-13 for 2 weeks delayed tumor growth similarly. Daily treatment of $50 \mathrm{mg} / \mathrm{kg} \mathrm{NH} 4-13$ showed a stronger anticancer effect. Overall, NH4-6 and NH4-13 had similar anticancer effects, but NH4-13, due to its SIRT2 selectivity, has much lower toxicity in vivo. Therefore, it could be advantageous to use SIRT2-selective inhibitors to treat cancers (Hong et al., 2021).

Through selective degradation of SIRT2, TM-P4-Thal treatment increased the acetylation level of $\alpha$-tubulin and fatty acylation level of K-Ras4a. Consequently, TM-P4-Thal showed a stronger antiproliferative effect in MCF7 and MDA-MB-231 breast cancer cells than TM at lower concentrations (Hong et al., 2020).

\section{SIRT3 Inhibitors in Cancer}

SIRT3 regulates various mitochondrial functions, such as ATP generation, metabolism and reactive oxygen species stabilization (Morris, 2013; Hu et al., 2014; Carafa et al., 2016). For example, SIRT3 deacetylates and activates glutamate dehydrogenase, a mitochondrial enzyme that converts glutamate to a-ketoglutarate (Plaitakis et al., 2017; Torrens-Mas et al., 2017). In the beginning, many studies reported SIRT3 as a tumor suppressor. SIRT3 attenuates the stabilization of HIF1a and regulates metabolic reprogramming (Bell et al., 2011; Finley et al., 2011). In breast cancer cell lines, SIRT3 is often less expressed, and the overexpression SIRT3 suppresses glycolysis and cell proliferation (Finley et al., 2011). Patient clinical data also confirmed this trend, as most breast cancer patients had significantly lower SIRT3 expression levels (Alhazzazi et al., 2011). Furthermore, SIRT3 knockout mice developed larger mammary gland tumors than the SIRT3 wild-type mice (Finley et al., 2011).

In contrast, many studies reported SIRT3 as a tumor activator. In bladder cancer cells, SIRT3 deacetylates and inactivates p53, which subsequently promotes cellular proliferation ( $\mathrm{Li}$ et al., 2010). Also, oral squamous cell carcinoma cells and tissues expressed higher SIRT3 levels (Alhazzazi et al., 2011). Diffusive large B cell lymphomas (DLBCL) required SIRT3 for anaplerotic metabolism, growth, survival, and autophagy. Furthermore, SIRT3 knockdown in DLBCL cells and mice significantly impaired cell proliferation and tumor growth (Li et al., 2019). As such, the role of SIRT3 is likely context and cancer type dependent.

In HNSCC and DLBCL cells, SIRT3 inhibitors have potently hindered cancer growth. By increasing reactive oxygen species (ROS) levels, LC-0296 reduced cell proliferation and promoted apoptosis of UM-SCC-1 and UM-SCC-17B HNSCC cells (Table 5). Meanwhile, LC-0296 did not affect the cell proliferation of normal human oral keratinocytes. Even though these HNSCC cells were resistant to radiation and cisplatin, LC0296 enhanced the effects of these treatments in HNSCC cells. In UM-SCC-17B cells, LC-2096 increased acetylation levels of NDUFA9 and GDH, SIRT3 deacetylation substrates, and thereby enhanced ROS levels (Alhazzazi et al., 2016).

Treatment of YC8-02 decreased cellular proliferation of OCLLY1, HBL1, Pfeiffer, SU-DHL4, TMD3, Karpas 422, and OCLLY7 lymphoma cells (Table 5). In a Karpas 422 tumor xenograft model, YC8-02 significantly impeded the tumor growth. Knockdown of SIRT3 in Karpas422, OCI-LY1, and HBL1 cells impaired cellular proliferation, and xenografted tumors of Karpas422 with knockdown SIRT3 in mice had slower growth. These knockdown results confirmed the therapeutic benefits of YC8-02 and targeting SIRT3 in DLBCLs (Li et al., 2019).

\section{SIRT5 Inhibitors in Cancer}

Many reports showed that SIRT5 has pro-tumor role. The SIRT5 mRNA level is often amplified in tumors compared to normal tissues (Igci et al., 2016; Bringman-Rodenbarger et al., 2018). SIRT5 regulates several metabolic pathways important in cancer, such as glycolysis, TCA, and urea cycle. For instance, SIRT5 demalonylates GAPDH to activate glycolysis (Nishida et al., 2015). Under oxidative stress, SIRT5 desuccinylates PKM2 to decrease the overall carbon flux in TCA cycles (Xiangyun et al., 2017). SIRT5 also activates LDHB, which induces autophagy and cell proliferation of HCT-116 colorectal cancer cells (Shi et al., 2019). Also, overexpression of SIRT5 in hepatocellular carcinoma cells promotes cell proliferation (Zhang et al., 2019). In breast cancer cells, SIRT5 desuccinylates and stabilizes glutaminase, which regulates the overall glutaminolysis, a key metabolic hallmark of cancers (Greene et al., 2019). In MDA-MB-231 and MDA-MB-468 breast, and A-549 lung cancer cells, knockdown of SIRT5 decreases cell proliferation and anchorage-independent growth. Moreover, in mouse xenograft studies, SIRT5-deficient MDA-MB-231 tumors were significantly smaller than wild-type tumors (Greene et al., 2019). In HCT-116 colorectal cancer cells, SIRT5 removes succinyl groups from K393 and K395 of citrate synthase. The hypersuccinylation of citrate synthase decreases cell proliferation and migration, which supports the tumorigenic role of SIRT5 (Ren et al., 2020). Lastly, SIRT5 promotes the proliferation of cutaneous melanoma genotypes, including uveal melanoma. In the A2058 melanoma tumor xenograft model, SIRT5 depletion significantly delayed the tumor growth (Giblin et al., 2021).

There is only one SIRT5 selective inhibitor, DK1-04e, that showed promising effect in cellular and animal cancer studies. In MCF7 and MDA-MB-231 breast cancer cells, treatment of DK1-04e inhibited both cell proliferation and anchorageindependent colony formation (Table 5). Furthermore, treatment with DK1-04e increased mitochondrial global succinylation in MCF7 cells. In both MMTV-PyMT and MDA-MB-231 tumor xenograft mouse models, DK1-04e significantly impaired the tumor growth without any bodyweight loss. The cytotoxicity of DK-104e was dependent on its SIRT5 inhibition. SIRT5 partial knockout in MDA-MB231 cells have impaired anchorage-independent colony formation. Furthermore, Sirt5 deletion PyMT mice had 
slower tumor growth and less metastasis. DK1-04e (O), an inactive derivative with an oxygen atom instead of the sulfur, showed weaker cytotoxicity than DK1-04e. Overall, DK1-04e studies showed that SIRT5 inhibition can be an effective treatment in breast cancer cells (Abril et al., 2021).

\section{SIRT6 Modulators in Cancer}

Through deacetylation and defatty-acylation, SIRT6 regulates numerous biological roles, including cell proliferation, DNA repair, and glucose metabolism (Jing and Lin, 2015; Kosciuk et al., 2019). SIRT6 deacetylates histone H3K9, H3K18, and H3K56 to suppress the activities of several transcriptional factors, such as c-Jun, and NF-kB (Michishita et al., 2008; Kawahara et al., 2009; Michishita et al., 2009; Sundaresan et al., 2012; Tasselli et al., 2016). SIRT6 removes fatty acyl groups from TNF- $\alpha$ to promote its secretion (Jiang et al., 2013). In cancers, SIRT6 is also viewed both as a tumor promoter and a tumor suppressor. As a tumor promoter, SIRT6 promotes cell cycle and tumor proliferation while inhibiting apoptosis (Garcia-Peterson et al., 2017; Huang et al., 2017). In the esophagus, thyroid, and melanocytes, SIRT6 is expressed higher than in normal tissues (Huang et al., 2017). As a tumor suppressor, SIRT6 is downregulated in colorectal, ovarian, breast, lung, pancreatic, and hepatocellular tumors (Marquardt et al., 2013; Zhang et al., 2015; Kugel et al., 2016). SIRT6 attenuates migration and invasion of ovarian cancer cells (Bae et al., 2018). SIRT6 deficient MEF cells proliferate faster than control wild-type cells and loss of SIRT6 induced faster tumor formation in mice (Sebastian et al., 2012). In colorectal cancer stem cells, SIRT6 impaired cellular proliferation and anchorage-independent colony formation (Sebastian et al., 2012). Furthermore, through defatty-acylating, SIRT6 regulates R-Ras2 localization, and subsequently hinders cell proliferation (Zhang et al., 2017).

The SIRT6 modulators' effects in cancer cells are summarized in Table 6. It is only recently that UBCS039 and MDL-800 were reported to activate SIRT6 and decrease proliferation of lung, hepatocellular carcinoma, and pancreatic cancer cells. For instance, UBCS039 induced autophagosome accumulation, thereby leading to apoptosis. UBCS060, an inactive analog of UBCS039, could not increase the autophagosome accumulation and autophagy-induced apoptosis (You et al., 2017). A previous report suggested that lack of SIRT6 decreased oxygen consumption and ATP level in the heart (Khan et al., 2018). In accordance with this, treatment of UBSC039 activated ROS production and increased ATP level in H1299 and HeLa cells (Iachettini et al., 2018).

MDL-800 significantly suppressed proliferation of BEL7405 cells in vitro and in mouse xenograft studies (Huang et al., 2018). MDL800 promoted cell cycle arrest in G0/G1 phase, as p21 and p27 expressions have increased, and CDK2, CDK4, cyclin D1, and cyclin D3 levels have decreased. To confirm whether the effect of MDL-800 depended on SIRT6 activation, SIRT6 knockout BEL6405 cells were treated with MDL-800. In these SIRT6 knockout cells, treatment of MDL-800 did not change any of the previously observed markers for the cell cycle arrest, confirming that the effect of MDL-800 was through SIRT6 activation (Huang et al., 2018). In addition to the hepatocellular carcinoma cells, MDL-800 inhibited the proliferation of 12 non-small cell lung cancer (NSCLC) cells from the NCI-60 screening. MDL-800 did not affect the proliferation of SIRT6knockout HCC827 and PC9 NSCLC cells, which confirmed the on-target activation of SIRT6 by MDL-800. In the HCC827 tumor xenograft mouse study, administration of MDL-800 increased histone $\mathrm{H} 3$ acetylation and significantly decreased the tumor growth (Shang et al., 2021).

In specific conditions, several SIRT6 inhibitors showed antiproliferative effects. As mentioned, Compound 2, 3, and 8 increased $\mathrm{H} 3 \mathrm{~K} 9$ acetylation in BxPC-3 pancreatic cancer cells (Sociali et al., 2015). Also, Compound 3 and 8 increased the glucose uptake in both BxPC-3 and L6 myoblasts. Among these three, only Compound 8 showed antiproliferative effect against BxPC-3 cells. Interestingly, Compound 2 and 3 showed synergistic effect with gemcitabine against proliferation of BxPC-3 cells (Sociali et al., 2015).

Compound 5 and 11 promoted glucose uptake and inhibited TNF- $\alpha$ production. Even though Compound 5 and 11 were not toxic, both SIRT6 inhibitors with gemcitabine showed a stronger anticancer effect in BxPC-3 cell proliferation. In the pharmacokinetics study, as Compound 5 showed a relatively short half-life, additional modifications on this compound are needed to improve the bioavailability, which will allow more accurate assessment in animal studies (Damonte et al., 2017).

\section{Pan-Sirtuin Inhibitors in Cancer}

In addition to the selective sirtuin inhibitors, numerous pansirtuin inhibitors were reported to decrease cancer cell proliferation. However, because treatment of these pan-sirtuin inhibitors may cause over-toxicity issues, extra caution is needed when using these inhibitors. In NCI-H460 lung cancer and HeLa cervical cancer cells, Cambinol increased acetylation levels of several sirtuin substrates, including p53, a-tubulin, FOXO3a, and $\mathrm{Ku} 70$ (Heltweg et al., 2006). In RPMI8226 and U266 multiple myeloma cells, Cambinol induced apoptosis, cell proliferation impairment, and cell cycle arrest by increasing p53, p21, cleaved PARP, and cleaved caspase 3 (Lu et al., 2021). In orthopedic tumor xenograft mice model with HepG2 hepatocarcinoma cells, Cambinol significantly reduced tumor growth, which was consistent with the SIRT1 knockdown results of in vivo intrahepatic xenograft mouse model (Portmann et al., 2013). Also, it was reported that SIRT1 stabilizes N-Myc protein and promote neuroblastoma cell proliferation. Thus, the knockout SIRT1 BE (2)-C cells had lower N-Myc level than the wild-type cells. In accordance with this, Cambinol treatment in TH-MYCN transgenic mice had decreased neuroblastoma formation (Marshall et al., 2011; Portmann et al., 2013). In HepG2 and Huh7 hepatocarcinoma cells, compared to a single treatment of sorafenib, a combination of Cambinol and sorafenib showed an enhanced effect in reducing cell proliferation, migration, and invasion (Ceballos et al., 2021).

In MCF7 breast and H1299 non-small lung cancer cells, treatment with Sirtinol led to senescence-like growth arrest and decreased activation of the RAS-MAPK pathway. Similar results were also observed with SIRT1 knockdown (Ota et al., 2006). Furthermore, Sirtinol reduced cell proliferation of H1299 non-small lung, PC3 prostrate, DU145 prostate, HeLa cervical, S1T adult T-cell leukemia/lymphoma (ATL), and Jurkat 
ATL cancer cells (Kojima et al., 2008; Kozako et al., 2012; Fong et al., 2014). In PC3, DU145, S1T and Jurkat cells, knockdown of SIRT1 also hindered cell proliferation (Kojima et al., 2008; Kozako et al., 2012). Combination treatment of sodium dichloroacetic acid (DCA) and Sirtinol led to synergistic anticancer effect in A549 and H129 NSCLC cells in vitro, and in vivo A549 tumor xenograft mice model (Ma et al., 2018).

Through SIRT1 inhibition, Salermide induced apoptosis in MOL4 acute lymphoblastic leukemia, SW480 colorectal, KG-1a acute myelogenous leukemia, and Raji Burkitt's lymphoma cells. Based on the knockdown studies of SIRT1 and SIRT2, Salermideinduced apoptosis is mainly through its SIRT1 inhibition (Lara et al., 2009). Furthermore, Salermide showed strong antiproliferative effects in BE (2)-C neuroblastoma and MIA$\mathrm{PaCa}-2$ pancreatic cancer cells, consistent with the results from SIRT2 knockdown. Furthermore, SIRT2 knockdown and $50 \mu \mathrm{M}$ of Salermide in these cell lines induced n-Myc and c-Myc degradation (Liu et al., 2013).

Even though Tenovin- 6 showed strong anti-cancer potency, Tenovin- 6 usage may be limited due to its off-target effect and potential over-toxicity issues, as mentioned earlier. In both cellular and tumor xenograft mice studies, Tenovin- 6 showed strong antiproliferative effects against ARN8 melanoma cells (Lain et al., 2008). In AGS, AGS-EBV, SNU-179, HGC-27, N87, SNU-1, and KATO-III gastric cancer cells, Tenovin-6 decreased the cell proliferation. Moreover, Tenovin- 6 hindered cell proliferation and anchorage-independent growth of AGS, AGS-EBV, and HGC-27 through increasing acetyl p53 levels (Ke et al., 2020). In A549 NSLCL cells, a combination of Tenovin-6 and metformin demonstrated a synergistic antiproliferative effect by HIC1-dependent SIRT1 level reduction (Lee et al., 2019). By increasing the expression of p53 and ROS level, Tenovin- 6 also attenuated migration and proliferation of 92.1, Mel-270, Omm-1, and Omm-2.3 uveal melanoma (UM) cells. Also, in 92.1, and Mel-270 cells, Tenovin-6 had a synergistic effect with Vinblastine, a chemotherapeutic agent for UM patients (Dai et al., 2016).

BZD9L1 showed antiproliferative effects in HCT-116 colorectal, CCRF-CEM leukemia, and MDA-MB-468 breast cancer cells (Tan et al., 2018). Furthermore, in HCT-116 and HT-29 colorectal cancer cells, BZD9L1 significantly decreased the cell migration and anchorage-independent growth (Tan et al., 2018). Only in HCT116 cells, BZD9L1 showed a synergistic anticancer effect with 5Fluorouracil, a conventional chemotherapeutic agent. The combination of BZD9L1 and 5-Fluorouracil increased cell cycle, arrest, and apoptosis, while it decreased the spheroid proliferation. In addition, the combination treatment of BZD9L1 and 5Fluorouracil significantly impaired tumor growth of HCT-116 in a tumor xenograft mouse study (Tan et al., 2019).

In U373 and Hs683 glioma cells, treatment of Compound 18 increased acetylation levels of histone $\mathrm{H} 4$, histone $\mathrm{H} 3 \mathrm{~K} 56$, and a-tubulin, which confirmed cellular inhibition of SIRT1 and SIRT2 (Schnekenburger et al., 2017). Consistent with the SIRT1 and SIRT2 knockdown results, Compound 18 impaired cell proliferation of U373 and Hs683 cells. Moreover, Compound 18 showed a broad anticancer effect, as its average $\mathrm{GI}_{50}$ was about $3 \mu \mathrm{M}$ in the NCI-60 screening. In the zebrafish xenotransplant model,
Compound 18 treatment significantly reduced the growth of fluorescent-labeled HS683 and U373 tumors (Schnekenburger et al., 2017).

Compound $3 \mathrm{~g}$ exerted stronger cytotoxicity than EX-527 in several cancer cell lines, K562 leukemia, HCT-116 colorectal, HT29 colorectal, H460 lung, A549 lung, and MCF7 breast cancer cells. Such increased potency of Compound $3 \mathrm{~g}$ from EX-527 could come from the dual inhibition of SIRT1 and SIRT2, but this was not confirmed in the study. Thus, future studies proving cellular inhibition of SIRT1 and SIRT2 by Compound $3 \mathrm{~g}$ will be needed (Laaroussi et al., 2020).

A SIRT1-3 inhibitor, MC2494 decreased metabolic activity and proliferation of U937 leukemia cells (Carafa et al., 2020). MC2494 decreased ATP production and expression levels of PGC1 $\alpha$ and PGC1 $\beta$, which are important for metabolic regulation. In addition, PGCla is present in the cytoplasm under normal condition, but more perinuclear PGC1a was detected, after treatment of MC2494 (Carafa et al., 2020).

JH-T4, a mechanism-based SIRT1-3 inhibitor, portrayed strong antiproliferative effects in a wide range of cancer cells, including MCF7 breast, MDA-MB-231 breast, HCT-116 colorectal, and NCI-H23 lung cancer cells. However, JH-T4 also affected the proliferation of normal epithelial cells like HME1 and MCF-10A. Thus, usage of JH-T4 may cause an over-toxicity problem in animal studies (Spiegelman et al., 2019).

\section{SIRTUIN MODULATORS IN NEUROLOGICAL DISEASES}

\section{SIRT1 Inhibitors in Neurological Diseases}

Both protective and detrimental effects of SIRT1 in neurological diseases have been reported. SIRT1 inhibits neurogenesis through inhibiting the transcriptional factors Hes1 and Mash1 (Prozorovski et al., 2008). SIRT1 maintains cognitive level and synaptic plasticity (Michan et al., 2010). The brain of SIRT1 knockout mice looked normal but showed a significant decrease in dendritic extension, length, and complexity (Michan et al., 2010). SIRT1 is also reported to promote neurite outgrowth through suppressing expression and phosphorylation of mTOR (Guo et al., 2011). The parietal cortex of Alzheimer's disease patients showed lower expression of SIRT1, which may be connected to an increase of $\beta$-amyloid and tau (Julien et al., 2009). In microglial cells, overexpression of SIRT1 decreased acetylation of RelA/p65 subunit of NF- $\kappa \beta$, which consequently inhibited NF- $\kappa \beta$ signaling induced by Amyloid- $\beta$ and neuronal death (Chen et al., 2005). Overexpression of SIRT1 decreases acetylation of FOXO3a, and consequently protects against huntingtin toxicity (Jeong et al., 2011). These reports highlights the beneficial effects of SIRT1 in the neurological system.

In contrast, other reports also point to the negative impacts of SIRT1 in neurological diseases. Knockdown of SIRT1 fostered neurogenesis of P19 embryonic carcinoma cells. SIRT1 inhibition by EX-527 also promoted the differentiation of P19 cells into functional neurons with around 50\% efficiency (Kim et al., 2016). 
In single prolonged stress (SPS) mice mimicking post-traumatic stress disorder (PTSD), Sirt1 deleted mice had less anxiety and freezing time, which indicated SIRT1 as a potential therapeutic target for PTSD. Osmotic delivery of EX-527 to ventral CA1 of hippocampus had deactivated helix-loop-helix transcription factor 2 and subsequently hindered the expression of MAO-A. This further led to the stabilization of serotonin. In addition, EX-527 ensured normal neuronal plasticity by decreasing dendritic spines and abnormal shapes (Li et al., 2019). Injection of EX-527 to the ventrolateral orbital cortex had ameliorated morphine addiction of rats. Morphine injected rats had elevated SIRT1 expression level, which got diminished with the administration of EX-527 (Wei et al., 2021). Lastly, in the rat model of middle cerebral artery occlusion, which simulates cerebral ischemia-reperfusion injury, EX-527 enhanced the survival rate and decreased cerebral infarction volume (Nikseresht et al., 2019). Lastly, EX-527 was tested in a clinical trial with patients with Huntington's Disease. EX-527 did not cause any adverse side-effect, but in a short 12 week trial, EX-527 did not affect the huntingtin level (Sussmuth et al., 2015). No further clinical study with EX-527 have been reported.

In the subarachnoid hemorrhage rat model, Sirtinol treatment lowered SIRT1 expression, which further induced damage of the blood-brain barrier and neurological ability. In addition, Sirtinol aggravated brain edema and increased endothelial cell apoptosis (Zhou et al., 2014). Thus, for subarachnoid hemorrhage, a validated potent SIRT1 activator should be tested as a potential treatment.

\section{SIRT2 Inhibitors in Neurological Diseases}

Through deacetylation of a-tubulin and activation of the CREB signaling pathway, SIRT2 promotes neuronal differentiation of mesenchymal stem cells (Jeong and Cho, 2017). In oligodendroglia and myelin sheets, SIRT2 is often highly expressed (Li et al., 2007). Through increasing the expression level of myelin basic proteins, SIRT2 boosts oligodendroglia differentiation (Ji et al., 2011). Also, because of the increased acetylated FOXO3a level and decreased Bim expression, SIRT2 knockout mice showed resistance against 1-methyl-4-phenyl1,2,3,6-tetrahydropyridine (MPTP), which induces neurotoxicity like Parkinson's Disease (Liu et al., 2014).

In accordance with the role of SIRT2, many SIRT2 inhibitors have been reported to ameliorate the symptoms from neurological disease. The SIRT2 inhibitor AGK2 showed a neuroprotective effect in Parkinson's Disease models. Releasing adenylate kinase to the media, AGK2 reduced a-Synuclein-mediated toxicity. a-Synuclein toxicity was decreased by SIRT2 knockdown in neuroglioma cells, which verified that the effect of AGK2 was from its SIRT2 inhibition. Also, AGK2 treatment increased viabilities of dopamine neurons in cellular and drosophila models (Outeiro et al., 2007). In mice, AGK2 ameliorated lipopolysaccharides (LPS)-induced neuroinflammation, decreasing LPS-induced CD11b TNF- $\alpha$, and IL-6 levels. AGK2 treatment in mice decreased TUNEL signals, which are indicators of brain apoptotic damage (Wang et al., 2016). In the middle cerebral artery occlusion (MCAO) mice model simulating focal ischemic stroke, AGK2 administration lowered cleaved-caspase 3, $\mathrm{Bim}$, and Bad, which consequently hindered apoptosis (She et al., 2018). Lastly, in cultured hippocampal neurons, AGK2 protected cell deaths from exposure to $\mathrm{H}_{2} \mathrm{O}_{2}$. Also, in the same study, AGK2 promoted VEGF and HO-1 mRNA levels, which stimulates neuroprotection against ischemic injury. This result was consistent with that from the experiments with SIRT2 knockout DT40 cells (Kaitsuka et al., 2020).

In the MCAO mouse model, the SIRT2-selective inhibitor AK7 decreased the infarction volume and promoted neurological recovery. Moreover, AK-7 increased the activation of a MAP kinase, $\mathrm{p} 38$, in vitro and in vivo, which led to the neuroprotection from the ischemic injury. Knockdown of SIRT2 also activated p38 in Neuro-2a cells (Wu et al., 2018). In the microglia from the sevoflurane-treated neonatal rat study, AK-7 decreased proinflammatory markers, while increasing anti-inflammatory markers. Sevoflurane is used as an inhalational anesthetic, which could damage the developing brain (Wu et al., 2020).

A nicotinamide-derived SIRT2 selective inhibitor, NCO-141 treatment had increased spatial learning and memory deficiency of 5 month-old senesce-accelerated mouse prone-8 (SAMP8) mice, which mimics Alzheimer's disease. In SAMP8 mice, treatment with a selective SIRT2 inhibitor NCO-141 did not indicate any therapeutic benefits. Nevertheless, NCO-141 increased glutamate receptor subunits GluN2A, GluN2B, and GluA1, which are essential for synaptic plasticity. To confirm whether NCO-141 inhibited SIRT2 in hippocampus, ATPbinding cassette transporter Abcal expression level was measured, as transcription of Abcal is inhibited by SIRT2. As expected, NCO-141 treated SAMP8 mice elevated level of Abca1 (Diaz-Perdigon et al., 2020). NCO-90-based SIRT2 inhibitor Compound 53 and pan SIRT1-3 inhibitor KPM-2 significantly promoted neurite outgrowth of Neuro-2a cells (Mellini et al., 2017; Mellini et al., 2019).

\section{SIRT6 Inhibitors in Neurological Diseases}

SIRT6 regulates stem cell differentiation and neuroectoderm development through its deacetylation of histone H3. SIRT6 knockout mice showed higher expressions of Oct4, Sox2, and Nanog, which are important for stem cell pluripotency. Consequently, this led to higher expression of Tet enzymes, which produces 5-hydroxymethylcytosine. With increased 5hydroxymethylcytosine, more embryonic stem cells differentiated into neuroectoderm. When SIRT6 was present, expressions of Oct4, Sox2, and Nanog were repressed, and led to balanced differentiation of embryonic stem cells (Etchegaray et al., 2015). For immunity and inflammation, SIRT6 de-fatty acylates TNFa and promotes its secretion. This could potentially regulate inflammatory cytokine production and necrosis (Jiang et al., 2013). Mice with brain-specific SIRT6 knockout showed behavioral abnormalities along with DNA damage and increased phosphorylated Tau. Also, in patients with Alzheimer's disease, lower expression of SIRT6 was measured, which hints the neuroprotective role of SIRT6 (Kaluski et al., 2017). Lastly, SIRT6 promotes the differentiation of dendritic cells in vitro and in vivo (Lasiglie et al., 2016).

Compound 1 is a SIRT6 inhibitor that had shown therapeutic effect in autoimmune encephalomyelitis (EAE), an animal model of multiple sclerosis (Ferrara et al., 2020). In a previous study, Compound 1 increased glucose uptake and GLUT-1 expression, 
and decreased TNF- $\alpha$ in BxPC-3 pancreatic cancer cells. These observations indicate a potent cellular SIRT6 inhibition by Compound 1 (Parenti et al., 2014). In C57bl/6 mice with MOG35-55 injection, which mimics EAE conditions, treatment with Compound 1 decreased the levels of TNFa and neurological impairments (Ferrara et al., 2020).

Since SIRT6 inhibitors may affect the development of neurological disorder, assessing SIRT6 activators in neurological disease models will be interesting, but so far there has been no report on this direction.

\section{SIRTUIN MODULATORS IN CARDIOVASCULAR DISEASES}

In addition to cancer and neurological disease, several sirtuins have been connected to cardiovascular diseases, like vascular aging, atherosclerosis, cardiac hypertrophy, and many more (Alcendor et al., 2004; Alcendor et al., 2007; Zhang et al., 2008; Balestrieri et al., 2015; D’Onofrio et al., 2016; Liu et al., 2016). Among these, several sirtuin modulators were specifically evaluated in cardiovascular diseases related to cardiomyocytes. Thus, we have summarized these SIRT1/2 and SIRT6 inhibitors.

\section{SIRT1/2 Inhibitors in Cardiovascular Diseases}

Mice lacking SIRT1 possess congenital cardiac abnormalities, and most could not survive beyond two weeks (Cheng et al., 2003). Also, SIRT1 deacetylates and regulates sodium channel Nav1.5. Deficiency of SIRT1 decreased expression of Nav1.5 in the cardiomyocyte membrane and induced cardiac abnormalities (Vikram et al., 2017). Low to moderate overexpression of SIRT1 in transgenic mouse inhibited fibrosis and cardiac hypertrophy. However, high overexpression of SIRT1 aggravated hypertrophy (Alcendor et al., 2007).

After Sirtinol treatment, neonatal rats showed a decrease in cardiomyocytes. In the same model, SIRT1 overexpression increased cardiomyocytes. Also, in the late phase of cardiac ischemia preconditioning in rats, treatment of Sirtinol significantly increased the infarct size, which made them more prone to the ischemia injury (Safari et al., 2017). Splitomicin, a yeast sirtuin inhibitor, had promoted carotid artery thrombus formation in a photochemical injury mouse study. In human endothelial cells, both SIRT1 siRNA and Splitomicin had increased and activated tissue factor protein, which promotes coagulation and thrombus formation. As the SIRT1 inhibitor worsens cardiovascular diseases, a reliable SIRT1 activator may be needed for the therapeutic benefit (Breitenstein et al., 2011). The potential cardiovascular effect of SIRT1 inhibitors may also limit the use of them for treating other diseases.

\section{SIRT6 Inhibitors in Cardiovascular Diseases} SIRT6 suppresses IGF-Akt signaling, which promotes heart failure when activated. SIRT6 knockout mice promoted cardiac hypertrophy upon hypertrophic stimulus (Sundaresan et al., 2012). In a mouse model of transverse aortic constriction (TAC)-induced heart failure, SIRT6 maintained telomere integrity, thereby decreasing cardiac fibrosis and infarct size (Li et al., 2017).

Consistent with the role of SIRT6 to prevent cardiovascular diseases, a SIRT6 inhibitor, OSS-128267, intensified diabetic cardiomyopathy (DCM). In a separate study using BxPC-3 pancreatic cells, OSS-128267 increased glucose uptake and GLUT-1 expression, and decreased TNF- $\alpha$, which suggests potent inhibition of SIRT6 (Parenti et al., 2014). In the mouse model of streptozotocin-induced diabetes and high glucosetreated cardiomyocytes, OSS-129167 promoted inflammation and oxidative stress, which led to diabetes-induced cardiomyocyte apoptosis (Huang et al., 2021). In this DCM disease model, treatment of SIRT6 activators like MDL-800 or UBCS039 may be beneficial.

\section{CONCLUDING REMARKS}

In this review, we have summarized the effects of various sirtuin modulators in cancer, neurological, and cardiovascular diseases. We anticipate that this review can help the readers to choose a suitable sirtuin modulator in different disease models. Overall, although there may be a few contradicting reports, some general trends can be extracted from the majority of the literature. SIRT2 and SIRT5 inhibitors showed rather consistent and promising effect in treating cancers. SIRT2 inhibitors have also showed beneficial effects in neurological diseases. On the other hand, SIRT1 and SIRT6 inhibitors have aggravated cardiovascular diseases, which underlines the need for a reliable SIRT1 and SIRT6 activators. These generalized trends support that the development of sirtuin modulators with enhanced potency and selectivity will be essential to further validate the preclinical data and explore the potential for treating various human diseases.

\section{AUTHOR CONTRIBUTIONS}

$\mathrm{NH}$ and HL conceived the concept, $\mathrm{NH}$ surveyed the literature and draft the manuscript, HL revised the manuscript.

\section{FUNDING}

The work is supported in part by grants from NIH/NCI CA 223534 and Falk Medical Research Foundation MCG-18448-20. 


\section{REFERENCES}

Abril, Y. L. N., Fernandez, I. R., Hong, J. Y., Chiang, Y. L., Kutateladze, D. A., Zhao, Q., et al. (2021). Pharmacological and Genetic Perturbation Establish SIRT5 as a Promising Target in Breast Cancer. Oncogene 40, 1644-1658. doi:10.1038/ s41388-020-01637-w

Aksoy, P., White, T. A., Thompson, M., and Chini, E. N. (2006). Regulation of Intracellular Levels of NAD: a Novel Role for CD38. Biochem. Biophys. Res. Commun. 345, 1386-1392. doi:10.1016/j.bbrc.2006.05.042

Alcendor, R. R., Gao, S., Zhai, P., Zablocki, D., Holle, E., Yu, X., et al. (2007). Sirt1 Regulates Aging and Resistance to Oxidative Stress in the Heart. Circ. Res. 100, 1512-1521. doi:10.1161/01.RES.0000267723.65696.4a

Alcendor, R. R., Kirshenbaum, L. A., Imai, S., Vatner, S. F., and Sadoshima, J. (2004). Silent Information Regulator 2alpha, a Longevity Factor and Class III Histone Deacetylase, Is an Essential Endogenous Apoptosis Inhibitor in Cardiac Myocytes. Circ. Res. 95, 971-980. doi:10.1161/01.RES.0000147557.75257.ff

Alhazzazi, T. Y., Kamarajan, P., Joo, N., Huang, J. Y., Verdin, E., D’Silva, N. J., et al. (2011). Sirtuin-3 (SIRT3), a Novel Potential Therapeutic Target for Oral Cancer. Cancer 117, 1670-1678. doi:10.1002/cncr.25676

Alhazzazi, T. Y., Kamarajan, P., Verdin, E., and Kapila, Y. L. (2011). SIRT3 and Cancer: Tumor Promoter or Suppressor? Biochim. Biophys. Acta 1816, 80-88. doi:10.1016/j.bbcan.2011.04.004

Alhazzazi, T. Y., Kamarajan, P., Xu, Y., Ai, T., Chen, L., Verdin, E., et al. (2016). A Novel Sirtuin-3 Inhibitor, LC-0296, Inhibits Cell Survival and Proliferation, and Promotes Apoptosis of Head and Neck Cancer Cells. Anticancer Res. 36, $49-60$.

Anderson, K. A., Huynh, F. K., Fisher-Wellman, K., Stuart, J. D., Peterson, B. S., Douros, J. D., et al. (2017). SIRT4 Is a Lysine Deacylase that Controls Leucine Metabolism and Insulin Secretion. Cell Metab. 25, 838-e15. doi:10.1016/j.cmet.2017.03.003

Asaka, R., Miyamoto, T., Yamada, Y., Ando, H., Mvunta, D. H., Kobara, H., et al. (2015). Sirtuin 1 Promotes the Growth and Cisplatin Resistance of Endometrial Carcinoma Cells: a Novel Therapeutic Target. Lab. Invest. 95, 1363-1373. doi:10.1038/labinvest.2015.119

Avalos, J. L., Bever, K. M., and Wolberger, C. (2005). Mechanism of Sirtuin Inhibition by Nicotinamide: Altering the $\mathrm{NAD}(+)$ Cosubstrate Specificity of a Sir2 Enzyme. Mol. Cell 17, 855-868. doi:10.1016/j.molcel.2005.02.022

Bae, J. S., Noh, S. J., Kim, K. M., Park, S. H., Hussein, U. K., Park, H. S., et al. (2018). SIRT6 Is Involved in the Progression of Ovarian Carcinomas via $\beta$-Catenin-Mediated Epithelial to Mesenchymal Transition. Front. Oncol. 8, 538. doi:10.3389/fonc.2018.00538

Balestrieri, M. L., Rizzo, M. R., Barbieri, M., Paolisso, P., D’Onofrio, N., Giovane, A., et al. (2015). Sirtuin 6 Expression and Inflammatory Activity in Diabetic Atherosclerotic Plaques: Effects of Incretin Treatment. Diabetes 64, 1395-1406. doi:10.2337/db14-1149

Beher, D., Wu, J., Cumine, S., Kim, K. W., Lu, S. C., Atangan, L., et al. (2009). Resveratrol Is Not a Direct Activator of SIRT1 Enzyme Activity. Chem. Biol. Drug Des. 74, 619-624. doi:10.1111/j.1747-0285.2009.00901.x

Bell, E. L., Emerling, B. M., Ricoult, S. J., and Guarente, L. (2011). SirT3 Suppresses Hypoxia Inducible Factor $1 \alpha$ and Tumor Growth by Inhibiting Mitochondrial ROS Production. Oncogene 30, 2986-2996. doi:10.1038/onc.2011.37

Bheda, P., Jing, H., Wolberger, C., and Lin, H. (2016). The Substrate Specificity of Sirtuins. Annu. Rev. Biochem. 85, 405-429. doi:10.1146/annurev-biochem-060815-014537

Blank, M. F., Chen, S., Poetz, F., Schnölzer, M., Voit, R., and Grummt, I. (2017). SIRT7-dependent Deacetylation of CDK9 Activates RNA Polymerase II Transcription. Nucleic Acids Res. 45, 2675-2686. doi:10.1093/nar/gkx053

Bonkowski, M. S., and Sinclair, D. A. (2016). Slowing Ageing by Design: the Rise of NAD+ and Sirtuin-Activating Compounds. Nat. Rev. Mol. Cell Biol. 17, 679-690. doi:10.1038/nrm.2016.93

Borra, M. T., Smith, B. C., and Denu, J. M. (2005). Mechanism of Human SIRT1 Activation by Resveratrol. J. Biol. Chem. 280, 17187-17195. doi:10.1074/ jbc.M501250200

Borradaile, N. M., and Pickering, J. G. (2009). NAD(+), Sirtuins, and Cardiovascular Disease. Curr. Pharm. Des. 15, 110-117. doi:10.2174/138161209787185742

Bosch-Presegué, L., and Vaquero, A. (2011). The Dual Role of Sirtuins in Cancer. Genes Cancer 2, 648-662. doi:10.1177/1947601911417862

Breitenstein, A., Stein, S., Holy, E. W., Camici, G. G., Lohmann, C., Akhmedov, A., et al. (2011). Sirt1 Inhibition Promotes In Vivo Arterial Thrombosis and Tissue Factor Expression in Stimulated Cells. Cardiovasc. Res. 89, 464-472. doi:10.1093/cvr/cvq339
Bringman-Rodenbarger, L. R., Guo, A. H., Lyssiotis, C. A., and Lombard, D. B. (2018). Emerging Roles for SIRT5 in Metabolism and Cancer. Antioxid. Redox Signal 28, 677-690. doi:10.1089/ars.2017.7264

Carafa, V., Nebbioso, A., Cuomo, F., Rotili, D., Cobellis, G., Bontempo, P., et al. (2018). RIP1-HAT1-SIRT Complex Identification and Targeting in Treatment and Prevention of Cancer. Clin. Cancer Res. 24, 2886-2900. doi:10.1158/10780432.CCR-17-3081

Carafa, V., Rotili, D., Forgione, M., Cuomo, F., Serretiello, E., Hailu, G. S., et al. (2016). Sirtuin Functions and Modulation: from Chemistry to the Clinic. Clin. Epigenetics 8, 61. doi:10.1186/s13148-016-0224-3

Carafa, V., Russo, R., Della Torre, L., Cuomo, F., Dell'Aversana, C., Sarno, F., et al. (2020). The Pan-Sirtuin Inhibitor MC2494 Regulates Mitochondrial Function in a Leukemia Cell Line. Front. Oncol. 10, 820. doi:10.3389/fonc.2020.00820

Ceballos, M. P., Angel, A., Delprato, C. B., Livore, V. I., Ferretti, A. C., Lucci, A., et al. (2021). Sirtuin 1 and 2 Inhibitors Enhance the Inhibitory Effect of Sorafenib in Hepatocellular Carcinoma Cells. Eur. J. Pharmacol. 892, 173736. doi:10.1016/j.ejphar.2020.173736

Cha, Y., Han, M. J., Cha, H. J., Zoldan, J., Burkart, A., Jung, J. H., et al. (2017). Metabolic Control of Primed Human Pluripotent Stem Cell Fate and Function by the miR-200c-SIRT2 axis. Nat. Cell Biol. 19, 445-456. doi: $10.1038 / \mathrm{ncb} 3517$

Chalkiadaki, A., and Guarente, L. (2015). The Multifaceted Functions of Sirtuins in Cancer. Nat. Rev. Cancer 15, 608-624. doi:10.1038/nrc3985

Chen, G., Zhang, B., Xu, H., Sun, Y., Shi, Y., Luo, Y., et al. (2017). Suppression of Sirt1 Sensitizes Lung Cancer Cells to WEE1 Inhibitor MK-1775-Induced DNA Damage and Apoptosis. Oncogene 36, 6863-6872. doi:10.1038/onc.2017.297

Chen, J., Cao, L., Li, Z., and Li, Y. (2019). SIRT1 Promotes GLUT1 Expression and Bladder Cancer Progression via Regulation of Glucose Uptake. Hum. Cell 32, 193-201. doi:10.1007/s13577-019-00237-5

Chen, J., Zhou, Y., Mueller-Steiner, S., Chen, L. F., Kwon, H., Yi, S., et al. (2005). SIRT1 Protects against Microglia-dependent Amyloid-Beta Toxicity through Inhibiting NF-kappaB Signaling. J. Biol. Chem. 280, 40364-40374. doi:10.1074/ jbc.M509329200

Chen, L. F., Mu, Y., and Greene, W. C. (2002). Acetylation of RelA at Discrete Sites Regulates Distinct Nuclear Functions of NF-kappaB. EMBO J. 21, 6539-6548. doi:10.1093/emboj/cdf660

Cheng, H. L., Mostoslavsky, R., Saito, S., Manis, J. P., Gu, Y., Patel, P., et al. (2003). Developmental Defects and P53 Hyperacetylation in Sir2 Homolog (SIRT1)Deficient Mice. Proc. Natl. Acad. Sci. U. S. A. 100, 10794-10799. doi:10.1073/ pnas. 1934713100

D’Onofrio, N., Servillo, L., Giovane, A., Casale, R., Vitiello, M., Marfella, R., et al. (2016). Ergothioneine Oxidation in the protection against High-Glucose Induced Endothelial Senescence: Involvement of SIRT1 and SIRT6. Free Radic. Biol. Med. 96, 211-222. doi:10.1016/j.freeradbiomed.2016.04.013

Dai, H., Kustigian, L., Carney, D., Case, A., Considine, T., Hubbard, B. P., et al. (2010). SIRT1 Activation by Small Molecules: Kinetic and Biophysical Evidence for Direct Interaction of Enzyme and Activator. J. Biol. Chem. 285, 32695-32703. doi:10.1074/jbc.M110.133892

Dai, H., Sinclair, D. A., Ellis, J. L., and Steegborn, C. (2018). Sirtuin Activators and Inhibitors: Promises, Achievements, and Challenges. Pharmacol. Ther. 188, 140-154. doi:10.1016/j.pharmthera.2018.03.004

Dai, W., Zhou, J., Jin, B., and Pan, J. (2016). Class III-specific HDAC Inhibitor Tenovin-6 Induces Apoptosis, Suppresses Migration and Eliminates Cancer Stem Cells in Uveal Melanoma. Sci. Rep. 6, 22622. doi:10.1038/srep22622

Damonte, P., Sociali, G., Parenti, M. D., Soncini, D., Bauer, I., Boero, S., et al. (2017). SIRT6 Inhibitors with Salicylate-like Structure Show Immunosuppressive and Chemosensitizing Effects. Bioorg. Med. Chem. 25, 5849-5858. doi:10.1016/j.bmc.2017.09.023

Diaz-Perdigon, T., Belloch, F. B., Ricobaraza, A., Elboray, E. E., Suzuki, T., Tordera, R. M., et al. (2020). Early Sirtuin 2 Inhibition Prevents Age-Related Cognitive Decline in a Senescence-Accelerated Mouse Model. Neuropsychopharmacology 45, 347-357. doi:10.1038/s41386-019-0503-8

Du, J., Zhou, Y., Su, X., Yu, J. J., Khan, S., Jiang, H., et al. (2011). Sirt5 Is a NADdependent Protein Lysine Demalonylase and Desuccinylase. Science 334, 806-809. doi:10.1126/science.1207861

Escande, C., Nin, V., Price, N. L., Capellini, V., Gomes, A. P., Barbosa, M. T., et al. (2013). Flavonoid Apigenin Is an Inhibitor of the NAD+ Ase CD38: Implications for Cellular NAD+ Metabolism, Protein Acetylation, and 
Treatment of Metabolic Syndrome. Diabetes 62, 1084-1093. doi:10.2337/db121139

Etchegaray, J. P., Chavez, L., Huang, Y., Ross, K. N., Choi, J., Martinez-Pastor, B., et al. (2015). The Histone Deacetylase SIRT6 Controls Embryonic Stem Cell Fate via TET-Mediated Production of 5-hydroxymethylcytosine. Nat. Cell Biol. 17, 545-557. doi:10.1038/ncb3147

Farooqi, A. S., Hong, J. Y., Cao, J., Lu, X., Price, I. R., Zhao, Q., et al. (2019). Novel Lysine-Based Thioureas as Mechanism-Based Inhibitors of Sirtuin 2 (SIRT2) with Anticancer Activity in a Colorectal Cancer Murine Model. J. Med. Chem. 62, 4131-4141. doi:10.1021/acs.jmedchem.9b00191

Feldman, J. L., Dittenhafer-Reed, K. E., and Denu, J. M. (2012). Sirtuin Catalysis and Regulation. J. Biol. Chem. 287, 42419-42427. doi:10.1074/jbc.R112.378877

Feldman, J. L., Dittenhafer-Reed, K. E., Kudo, N., Thelen, J. N., Ito, A., Yoshida, M., et al. (2015). Kinetic and Structural Basis for Acyl-Group Selectivity and $\mathrm{NAD}(+)$ Dependence in Sirtuin-Catalyzed Deacylation. Biochemistry 54, 3037-3050. doi:10.1021/acs.biochem.5b00150

Ferrara, G., Benzi, A., Sturla, L., Marubbi, D., Frumento, D., Spinelli, S., et al. (2020). Sirt6 Inhibition Delays the Onset of Experimental Autoimmune Encephalomyelitis by Reducing Dendritic Cell Migration. J. Neuroinflammation 17, 228. doi:10.1186/s12974-020-01906-1

Finley, L. W., Carracedo, A., Lee, J., Souza, A., Egia, A., Zhang, J., et al. (2011). SIRT3 Opposes Reprogramming of Cancer Cell Metabolism through HIF1a Destabilization. Cancer Cell 19, 416-428. doi:10.1016/j.ccr.2011.02.014

Fong, Y., Lin, Y. C., Wu, C. Y., Wang, H. M., Lin, L. L., Chou, H. L., et al. (2014). The Antiproliferative and Apoptotic Effects of Sirtinol, a Sirtuin Inhibitor on Human Lung Cancer Cells by Modulating Akt/ $\beta$-Catenin-Foxo3a axis. Scientific World Journal 2014, 937051. doi:10.1155/2014/937051

Fujita, Y., and Yamashita, T. (2018). Sirtuins in Neuroendocrine Regulation and Neurological Diseases. Front. Neurosci. 12, 778. doi:10.3389/ fnins.2018.00778

Funato, K., Hayashi, T., Echizen, K., Negishi, L., Shimizu, N., Koyama-Nasu, R., et al. (2018). SIRT2-mediated Inactivation of P73 Is Required for Glioblastoma Tumorigenicity. EMBO Rep. 19, e45587. doi:10.15252/embr.201745587

Garcia-Peterson, L. M., Ndiaye, M. A., Singh, C. K., Chhabra, G., Huang, W., and Ahmad, N. (2017). SIRT6 Histone Deacetylase Functions as a Potential Oncogene in Human Melanoma. Genes Cancer 8, 701-712. doi:10.18632/ genesandcancer.153

Gertz, M., Fischer, F., Nguyen, G. T., Lakshminarasimhan, M., Schutkowski, M., Weyand, M., et al. (2013). Ex-527 Inhibits Sirtuins by Exploiting Their Unique NAD+-dependent Deacetylation Mechanism. Proc. Natl. Acad. Sci. U. S. A. 110, E2772-E2781. doi:10.1073/pnas.1303628110

Ghosh, A., Sengupta, A., Seerapu, G. P. K., Nakhi, A., Shivaji Ramarao, E. V. V., Bung, N., et al. (2017). A Novel SIRT1 Inhibitor, 4bb Induces Apoptosis in HCT116 Human colon Carcinoma Cells Partially by Activating P53. Biochem. Biophys. Res. Commun. 488, 562-569. doi:10.1016/j.bbrc.2017.05.089

Giblin, W., Bringman-Rodenbarger, L., Guo, A. H., Kumar, S., Monovich, A. C., Mostafa, A. M., et al. (2021). The Deacylase SIRT5 Supports Melanoma Viability by Influencing Chromatin Dynamics. J. Clin. Invest. 131, e138926. doi:10.1172/jci138926

Gomes, P., Leal, H., Mendes, A. F., Reis, F., and Cavadas, C. (2019). Dichotomous Sirtuins: Implications for Drug Discovery in Neurodegenerative and Cardiometabolic Diseases. Trends Pharmacol. Sci. 40, 1021-1039. doi:10.1016/j.tips.2019.09.003

Greene, K. S., Lukey, M. J., Wang, X., Blank, B., Druso, J. E., Lin, M. J., et al. (2019). SIRT5 Stabilizes Mitochondrial Glutaminase and Supports Breast Cancer Tumorigenesis. Proc. Natl. Acad. Sci. U. S. A. 116, 26625. doi:10.1073/ pnas. 1911954116

Grozinger, C. M., Chao, E. D., Blackwell, H. E., Moazed, D., and Schreiber, S. L. (2001). Identification of a Class of Small Molecule Inhibitors of the Sirtuin Family of NAD-dependent Deacetylases by Phenotypic Screening. J. Biol. Chem. 276, 38837-38843. doi:10.1074/jbc.M106779200

Guo, W., Qian, L., Zhang, J., Zhang, W., Morrison, A., Hayes, P., et al. (2011). Sirt1 Overexpression in Neurons Promotes Neurite Outgrowth and Cell Survival through Inhibition of the mTOR Signaling. J. Neurosci. Res. 89, 1723-1736. doi:10.1002/jnr.22725

Haigis, M. C., and Sinclair, D. A. (2010). Mammalian Sirtuins: Biological Insights and Disease Relevance. Annu. Rev. Pathol. 5, 253-295. doi:10.1146/ annurev.pathol.4.110807.092250
Han, M. K., Song, E. K., Guo, Y., Ou, X., Mantel, C., and Broxmeyer, H. E. (2008). SIRT1 Regulates Apoptosis and Nanog Expression in Mouse Embryonic Stem Cells by Controlling P53 Subcellular Localization. Cell Stem Cell 2, 241-251. doi:10.1016/j.stem.2008.01.002

Heltweg, B., Gatbonton, T., Schuler, A. D., Posakony, J., Li, H., Goehle, S., et al. (2006). Antitumor Activity of a Small-Molecule Inhibitor of Human Silent Information Regulator 2 Enzymes. Cancer Res. 66, 4368-4377. doi:10.1158/ 0008-5472.CAN-05-3617

Hong, J. Y., Fernandez, I., Anmangandla, A., Lu, X., Bai, J. J., and Lin, H. (2021). Pharmacological Advantage of SIRT2-Selective versus Pan-SIRT1-3 Inhibitors. ACS Chem. Biol. 16, 1266-1275. doi:10.1021/acschembio.1c00331

Hong, J. Y., Jing, H., Price, I. R., Cao, J., Bai, J. J., and Lin, H. (2020). Simultaneous Inhibition of SIRT2 Deacetylase and Defatty-Acylase Activities via a PROTAC Strategy. ACS Med. Chem. Lett. 11, 2305-2311. doi:10.1021/acsmedchemlett.0c00423

Howitz, K. T., Bitterman, K. J., Cohen, H. Y., Lamming, D. W., Lavu, S., Wood, J. G., et al. (2003). Small Molecule Activators of Sirtuins Extend Saccharomyces cerevisiae Lifespan. Nature 425, 191-196. doi:10.1038/nature01960

Hu, J., Jing, H., and Lin, H. (2014). Sirtuin Inhibitors as Anticancer Agents. Future Med. Chem. 6, 945-966. doi:10.4155/fmc.14.44

Huang, H., Zhang, D., Wang, Y., Perez-Neut, M., Han, Z., Zheng, Y. G., et al. (2018). Lysine Benzoylation Is a Histone Mark Regulated by SIRT2. Nat. Commun. 9, 3374. doi:10.1038/s41467-018-05567-w

Huang, N., Liu, Z., Zhu, J., Cui, Z., Li, Y., Yu, Y., et al. (2017). Sirtuin 6 Plays an Oncogenic Role and Induces Cell Autophagy in Esophageal Cancer Cells. Tumour Biol. 39, 1010428317708532. doi:10.1177/1010428317708532

Huang, Y., Zhang, J., Xu, D., Peng, Y., Jin, Y., and Zhang, L. (2021). SIRT6 Specific Inhibitor OSS128167 Exacerbates Diabetic Cardiomyopathy by Aggravating Inflammation and Oxidative Stress. Mol. Med. Rep. 23, 367. doi:10.3892/ mmr.2021.12006

Huang, Z., Zhao, J., Deng, W., Chen, Y., Shang, J., Song, K., et al. (2018). Identification of a Cellularly Active SIRT6 Allosteric Activator. Nat. Chem. Biol. 14, 1118-1126. doi:10.1038/s41589-018-0150-0

Hubbard, B. P., Gomes, A. P., Dai, H., Li, J., Case, A. W., Considine, T., et al. (2013). Evidence for a Common Mechanism of SIRT1 Regulation by Allosteric Activators. Science 339, 1216-1219. doi:10.1126/science.1231097

Hubbard, B. P., and Sinclair, D. A. (2014). Small Molecule SIRT1 Activators for the Treatment of Aging and Age-Related Diseases. Trends Pharmacol. Sci. 35, 146-154. doi:10.1016/j.tips.2013.12.004

Iachettini, S., Trisciuoglio, D., Rotili, D., Lucidi, A., Salvati, E., Zizza, P., et al. (2018). Pharmacological Activation of SIRT6 Triggers Lethal Autophagy in Human Cancer Cells. Cell Death Dis. 9, 996. doi:10.1038/s41419-0181065-0

Igase, M., Fujiki, N., Shibutani, S., Sakai, H., Noguchi, S., Nemoto, Y., et al. (2020). Tenovin-6 Induces the SIRT-independent Cell Growth Suppression and Blocks Autophagy Flux in Canine Hemangiosarcoma Cell Lines. Exp. Cell Res. 388, 111810. doi:10.1016/j.yexcr.2019.111810

Igci, M., Kalender, M. E., Borazan, E., Bozgeyik, I., Bayraktar, R., Bozgeyik, E., et al. (2016). High-throughput Screening of Sirtuin Family of Genes in Breast Cancer. Gene 586, 123-128. doi:10.1016/j.gene.2016.04.023

Iside, C., Scafuro, M., Nebbioso, A., and Altucci, L. (2020). SIRT1 Activation by Natural Phytochemicals: An Overview. Front. Pharmacol. 11, 1225. doi:10.3389/fphar.2020.01225

Jeong, H., Cohen, D. E., Cui, L., Supinski, A., Savas, J. N., Mazzulli, J. R., et al. (2011). Sirt1 Mediates Neuroprotection from Mutant Huntingtin by Activation of the TORC1 and CREB Transcriptional Pathway. Nat. Med. 18, 159-165. doi: $10.1038 / \mathrm{nm} .2559$

Jeong, S. G., and Cho, G. W. (2017). The Tubulin Deacetylase Sirtuin-2 Regulates Neuronal Differentiation through the ERK/CREB Signaling Pathway. Biochem. Biophys. Res. Commun. 482, 182-187. doi:10.1016/j.bbrc.2016.11.031

Ji, S., Doucette, J. R., and Nazarali, A. J. (2011). Sirt2 Is a Novel In Vivo Downstream Target of Nkx2.2 and Enhances Oligodendroglial Cell Differentiation. J. Mol. Cell. Biol. 3, 351-359. doi:10.1093/jmcb/mjr009

Jiang, H., Khan, S., Wang, Y., Charron, G., He, B., Sebastian, C., et al. (2013). SIRT6 Regulates TNF- $\alpha$ Secretion through Hydrolysis of Long-Chain Fatty Acyl Lysine. Nature 496, 110-113. doi:10.1038/nature12038

Jin, J., He, B., Zhang, X., Lin, H., and Wang, Y. (2016). SIRT2 Reverses 4Oxononanoyl Lysine Modification on Histones. J. Am. Chem. Soc. 138, 12304-12307. doi:10.1021/jacs.6b04977 
Jing, H., Hu, J., He, B., Negrón Abril, Y. L., Stupinski, J., Weiser, K., et al. (2016). A SIRT2-Selective Inhibitor Promotes C-Myc Oncoprotein Degradation and Exhibits Broad Anticancer Activity. Cancer Cell 29, 297-310. doi:10.1016/ j.ccell.2016.04.005

Jing, H., and Lin, H. (2015). Sirtuins in Epigenetic Regulation. Chem. Rev. 115, 2350-2375. doi:10.1021/cr500457h

Jing, H., Zhang, X., Wisner, S. A., Chen, X., Spiegelman, N. A., Linder, M. E., et al. (2017). SIRT2 and Lysine Fatty Acylation Regulate the Transforming Activity of K-Ras4a. eLife 6, e32436. doi:10.7554/eLife.32436

Julien, C., Tremblay, C., Emond, V., Lebbadi, M., Salem, N., Jr., Bennett, D. A., et al. (2009). Sirtuin 1 Reduction Parallels the Accumulation of Tau in Alzheimer Disease. J. Neuropathol. Exp. Neurol. 68, 48-58. doi:10.1097/NEN.0b013e3181922348

Kaitsuka, T., Matsushita, M., and Matsushita, N. (2020). SIRT2 Inhibition Activates Hypoxia-Inducible Factor $1 \alpha$ Signaling and Mediates Neuronal Survival. Biochem. Biophys. Res. Commun. 529, 957-962. doi:10.1016/ j.bbrc.2020.06.159

Kaluski, S., Portillo, M., Besnard, A., Stein, D., Einav, M., Zhong, L., et al. (2017). Neuroprotective Functions for the Histone Deacetylase SIRT6. Cell Rep. 18, 3052-3062. doi:10.1016/j.celrep.2017.03.008

Kawahara, T. L., Michishita, E., Adler, A. S., Damian, M., Berber, E., Lin, M., et al. (2009). SIRT6 Links Histone H3 Lysine 9 Deacetylation to NF-kappaBdependent Gene Expression and Organismal Life Span. Cell 136, 62-74. doi:10.1016/j.cell.2008.10.052

Ke, X., Qin, Q., Deng, T., Liao, Y., and Gao, S. J. (2020). Heterogeneous Responses of Gastric Cancer Cell Lines to Tenovin-6 and Synergistic Effect with Chloroquine. Cancers (Basel) 12, 365. doi:10.3390/cancers12020365

Khan, D., Sarikhani, M., Dasgupta, S., Maniyadath, B., Pandit, A. S., Mishra, S., et al. (2018). SIRT6 Deacetylase Transcriptionally Regulates Glucose Metabolism in Heart. J. Cell. Physiol. 233, 5478-5489. doi:10.1002/ jcp. 26434

Kim, B. S., Lee, C. H., Chang, G. E., Cheong, E., and Shin, I. (2016). A Potent and Selective Small Molecule Inhibitor of Sirtuin 1 Promotes Differentiation of Pluripotent P19 Cells into Functional Neurons. Sci. Rep. 6, 34324. doi:10.1038/ srep34324

Kim, H. B., Lee, S. H., Um, J. H., Kim, M. J., Hyun, S. K., Gong, E. J., et al. (2015). Sensitization of Chemo-Resistant Human Chronic Myeloid Leukemia Stemlike Cells to Hsp90 Inhibitor by SIRT1 Inhibition. Int. J. Biol. Sci. 11, 923-934. doi:10.7150/ijbs.10896

Kim, H. S., Vassilopoulos, A., Wang, R. H., Lahusen, T., Xiao, Z., Xu, X., et al. (2011). SIRT2 Maintains Genome Integrity and Suppresses Tumorigenesis through Regulating APC/C Activity. Cancer Cell 20, 487-499. doi:10.1016/ j.ccr.2011.09.004

Kojima, K., Ohhashi, R., Fujita, Y., Hamada, N., Akao, Y., Nozawa, Y., et al. (2008). A Role for SIRT1 in Cell Growth and Chemoresistance in Prostate Cancer PC3 and DU145 Cells. Biochem. Biophys. Res. Commun. 373, 423-428. doi:10.1016/ j.bbrc.2008.06.045

Kokkonen, P., Rahnasto-Rilla, M., Mellini, P., Jarho, E., Lahtela-Kakkonen, M., and Kokkola, T. (2014). Studying SIRT6 Regulation Using H3K56 Based Substrate and Small Molecules. Eur. J. Pharm. Sci. 63, 71-76. doi:10.1016/ j.ejps.2014.06.015

Kosciuk, T., Price, I. R., Zhang, X., Zhu, C., Johnson, K. N., Zhang, S., et al. (2020). NMT1 and NMT2 Are Lysine Myristoyltransferases Regulating the ARF6 GTPase Cycle. Nat. Commun. 11, 1067. doi:10.1038/s41467-020-14893-x

Kosciuk, T., Wang, M., Hong, J. Y., and Lin, H. (2019). Updates on the Epigenetic Roles of Sirtuins. Curr. Opin. Chem. Biol. 51, 18-29. doi:10.1016/j.cbpa.2019.01.023

Kozako, T., Aikawa, A., Shoji, T., Fujimoto, T., Yoshimitsu, M., Shirasawa, S., et al. (2012). High Expression of the Longevity Gene Product SIRT1 and Apoptosis Induction by Sirtinol in Adult T-Cell Leukemia Cells. Int. J. Cancer 131, 2044-2055. doi:10.1002/ijc.27481

Kozako, T., Mellini, P., Ohsugi, T., Aikawa, A., Uchida, Y. I., Honda, S. I., et al. (2018). Novel Small Molecule SIRT2 Inhibitors Induce Cell Death in Leukemic Cell Lines. BMC Cancer 18, 791. doi:10.1186/s12885-018-4710-1

Kozako, T., Suzuki, T., Yoshimitsu, M., Uchida, Y., Kuroki, A., Aikawa, A., et al. (2015). Novel Small-Molecule SIRT1 Inhibitors Induce Cell Death in Adult T-Cell Leukaemia Cells. Sci. Rep. 5, 11345. doi:10.1038/srep11345

Kudo, N., Ito, A., Arata, M., Nakata, A., and Yoshida, M. (2018). Identification of a Novel Small Molecule that Inhibits Deacetylase but Not Defatty-Acylase
Reaction Catalysed by SIRT2. Philos. Trans. R. Soc. Lond. B Biol. Sci. 373, 20170070. doi:10.1098/rstb.2017.0070

Kugel, S., Sebastián, C., Fitamant, J., Ross, K. N., Saha, S. K., Jain, E., et al. (2016). SIRT6 Suppresses Pancreatic Cancer through Control of Lin28b. Cell 165, 1401-1415. doi:10.1016/j.cell.2016.04.033

Kumar, S., and Lombard, D. B. (2017). For Certain, SIRT4 Activities!. Trends Biochem. Sci. 42, 499-501. doi:10.1016/j.tibs.2017.05.008

Laaroussi, H., Ding, Y., Teng, Y., Deschamps, P., Vidal, M., Yu, P., et al. (2020) Synthesis of Indole Inhibitors of Silent Information Regulator 1 (SIRT1), and Their Evaluation as Cytotoxic Agents. Eur. J. Med. Chem. 202, 112561. doi:10.1016/j.ejmech.2020.112561

Lain, S., Hollick, J. J., Campbell, J., Staples, O. D., Higgins, M., Aoubala, M., et al. (2008). Discovery, In Vivo Activity, and Mechanism of Action of a SmallMolecule P53 Activator. Cancer Cell 13, 454-463. doi:10.1016/ j.ccr.2008.03.004

Lara, E., Mai, A., Calvanese, V., Altucci, L., Lopez-Nieva, P., Martinez-Chantar, M. L., et al. (2009). Salermide, a Sirtuin Inhibitor with a strong Cancer-specific Proapoptotic Effect. Oncogene 28, 781-791. doi:10.1038/onc.2008.436

Lasigliè, D., Boero, S., Bauer, I., Morando, S., Damonte, P., Cea, M., et al. (2016). Sirt6 Regulates Dendritic Cell Differentiation, Maturation, and Function. Aging (Albany NY) 8, 34-49. doi:10.18632/aging.100870

Lee, B. B., Kim, Y., Kim, D., Cho, E. Y., Han, J., Kim, H. K., et al. (2019). Metformin and Tenovin-6 Synergistically Induces Apoptosis through LKB1-independent SIRT1 Down-Regulation in Non-small Cell Lung Cancer Cells. J. Cell Mol. Med. 23, 2872-2889. doi:10.1111/jcmm.14194

Lee, H. C. (2006). Structure and Enzymatic Functions of Human CD38. Mol. Med. 12, 317-323. doi:10.2119/2006-00086.Lee

Li, M., Chiang, Y. L., Lyssiotis, C. A., Teater, M. R., Hong, J. Y., Shen, H., et al. (2019). Non-oncogene Addiction to SIRT3 Plays a Critical Role in Lymphomagenesis. Cancer Cell 35, 916-e9. doi:10.1016/j.ccell.2019.05.002

Li, S., Banck, M., Mujtaba, S., Zhou, M. M., Sugrue, M. M., and Walsh, M. J. (2010). p53-induced Growth Arrest Is Regulated by the Mitochondrial SirT3 Deacetylase. PLoS One 5, e10486. doi:10.1371/journal.pone.0010486

Li, W., Guo, B., Tao, K., Li, F., Liu, Z., Yao, H., et al. (2019). Inhibition of SIRT1 in Hippocampal CA1 Ameliorates PTSD-like Behaviors in Mice by Protections of Neuronal Plasticity and Serotonin Homeostasis via NHLH2/MAO-A Pathway. Biochem. Biophys. Res. Commun. 518, 344-350. doi:10.1016/ j.bbrc.2019.08.060

Li, W., Zhang, B., Tang, J., Cao, Q., Wu, Y., Wu, C., et al. (2007). Sirtuin 2, a Mammalian Homolog of Yeast Silent Information Regulator-2 Longevity Regulator, Is an Oligodendroglial Protein that Decelerates Cell Differentiation through Deacetylating Alpha-Tubulin. J. Neurosci. 27, 2606-2616. doi:10.1523/JNEUROSCI.4181-06.2007

Li, Y., Meng, X., Wang, W., Liu, F., Hao, Z., Yang, Y., et al. (2017). Cardioprotective Effects of SIRT6 in a Mouse Model of Transverse Aortic Constriction-Induced Heart Failure. Front. Physiol. 8, 394. doi:10.3389/fphys.2017.00394

Li, Y., Zhang, M., Dorfman, R. G., Pan, Y., Tang, D., Xu, L., et al. (2018). SIRT2 Promotes the Migration and Invasion of Gastric Cancer through RAS/ERK/ JNK/MMP-9 Pathway by Increasing PEPCK1-Related Metabolism. Neoplasia 20, 745-756. doi:10.1016/j.neo.2018.03.008

Lim, J. H., Lee, Y. M., Chun, Y. S., Chen, J., Kim, J. E., and Park, J. W. (2010). Sirtuin 1 Modulates Cellular Responses to Hypoxia by Deacetylating HypoxiaInducible Factor 1alpha. Mol. Cell 38, 864-878. doi:10.1016/ j.molcel.2010.05.023

Liu, L., Arun, A., Ellis, L., Peritore, C., and Donmez, G. (2014). SIRT2 Enhances 1Methyl-4-Phenyl-1,2,3,6-Tetrahydropyridine (MPTP)-induced Nigrostriatal Damage via Apoptotic Pathway. Front. Aging Neurosci. 6, 184. doi:10.3389/ fnagi.2014.00184

Liu, P. Y., Xu, N., Malyukova, A., Scarlett, C. J., Sun, Y. T., Zhang, X. D., et al. (2013). The Histone Deacetylase SIRT2 Stabilizes Myc Oncoproteins. Cell Death Differ 20, 503-514. doi:10.1038/cdd.2012.147

Liu, Z., Wang, J., Huang, X., Li, Z., and Liu, P. (2016). Deletion of Sirtuin 6 Accelerates Endothelial Dysfunction and Atherosclerosis in Apolipoprotein E-Deficient Mice. Transl. Res. 172, 18-e2. doi:10.1016/j.trsl.2016.02.005

Lu, B., Zhang, D., Wang, X., Lin, D., Chen, Y., and Xu, X. (2021). Targeting SIRT1 to Inhibit the Proliferation of Multiple Myeloma Cells. Oncol. Lett. 21, 306. doi:10.3892/ol.2021.12567 
Ma, W., Zhao, X., Wang, K., Liu, J., and Huang, G. (2018). Dichloroacetic Acid (DCA) Synergizes with the SIRT2 Inhibitor Sirtinol and AGK2 to Enhance Anti-tumor Efficacy in Non-small Cell Lung Cancer. Cancer Biol. Ther. 19, 835-846. doi:10.1080/15384047.2018.1480281

Machado de Oliveira, R., Sarkander, J., Kazantsev, A. G., and Outeiro, T. F. (2012). SIRT2 as a Therapeutic Target for Age-Related Disorders. Front. Pharmacol. 3, 82. doi:10.3389/fphar.2012.00082

Mai, A., Massa, S., Lavu, S., Pezzi, R., Simeoni, S., Ragno, R., et al. (2005). Design, Synthesis, and Biological Evaluation of Sirtinol Analogues as Class III Histone/ protein Deacetylase (Sirtuin) Inhibitors. J. Med. Chem. 48, 7789-7795. doi:10.1021/jm0501001

Mangas-Sanjuan, V., Oláh, J., Gonzalez-Alvarez, I., Lehotzky, A., Tökési, N., Bermejo, M., et al. (2015). Tubulin Acetylation Promoting Potency and Absorption Efficacy of Deacetylase Inhibitors. Br. J. Pharmacol. 172, 829-840. doi:10.1111/bph.12946

Marquardt, J. U., Fischer, K., Baus, K., Kashyap, A., Ma, S., Krupp, M., et al. (2013). Sirtuin-6-dependent Genetic and Epigenetic Alterations Are Associated with Poor Clinical Outcome in Hepatocellular Carcinoma Patients. Hepatology 58, 1054-1064. doi:10.1002/hep.26413

Marshall, G. M., Liu, P. Y., Gherardi, S., Scarlett, C. J., Bedalov, A., Xu, N., et al. (2011). SIRT1 Promotes N-Myc Oncogenesis through a Positive Feedback Loop Involving the Effects of MKP3 and ERK on N-Myc Protein Stability. Plos Genet. 7, e1002135. doi:10.1371/journal.pgen.1002135

Mathias, R. A., Greco, T. M., Oberstein, A., Budayeva, H. G., Chakrabarti, R., Rowland, E. A., et al. (2014). Sirtuin 4 Is a Lipoamidase Regulating Pyruvate Dehydrogenase Complex Activity. Cell 159, 1615-1625. doi:10.1016/ j.cell.2014.11.046

McCarthy, A. R., Pirrie, L., Hollick, J. J., Ronseaux, S., Campbell, J., Higgins, M., et al. (2012). Synthesis and Biological Characterisation of Sirtuin Inhibitors Based on the Tenovins. Bioorg. Med. Chem. 20, 1779-1793. doi:10.1016/ j.bmc.2012.01.001

Mellini, P., Itoh, Y., Elboray, E. E., Tsumoto, H., Li, Y., Suzuki, M., et al. (2019). Identification of Diketopiperazine-Containing 2-Anilinobenzamides as Potent Sirtuin 2 (SIRT2)-Selective Inhibitors Targeting the "Selectivity Pocket", Substrate-Binding Site, and NAD+-Binding Site. J. Med. Chem. 62, 5844-5862. doi:10.1021/acs.jmedchem.9b00255

Mellini, P., Itoh, Y., Tsumoto, H., Li, Y., Suzuki, M., Tokuda, N., et al. (2017). Potent Mechanism-Based Sirtuin-2-Selective Inhibition by an In Situ-generated Occupant of the Substrate-Binding Site, "selectivity Pocket" and NAD+binding Site. Chem. Sci. 8, 6400-6408. doi:10.1039/c7sc02738a

Menssen, A., Hydbring, P., Kapelle, K., Vervoorts, J., Diebold, J., Lüscher, B., et al. (2012). The C-MYC Oncoprotein, the NAMPT Enzyme, the SIRT1-Inhibitor DBC1, and the SIRT1 Deacetylase Form a Positive Feedback Loop. Proc. Natl. Acad. Sci. U S A. 109, E187-E196. doi:10.1073/pnas.1105304109

Michán, S., Li, Y., Chou, M. M., Parrella, E., Ge, H., Long, J. M., et al. (2010). SIRT1 Is Essential for normal Cognitive Function and Synaptic Plasticity. J. Neurosci. 30, 9695-9707. doi:10.1523/JNEUROSCI.0027-10.2010

Michishita, E., McCord, R. A., Berber, E., Kioi, M., Padilla-Nash, H., Damian, M., et al. (2008). SIRT6 Is a Histone H3 Lysine 9 Deacetylase that Modulates Telomeric Chromatin. Nature 452, 492-496. doi:10.1038/nature06736

Michishita, E., McCord, R. A., Boxer, L. D., Barber, M. F., Hong, T., Gozani, O., et al. (2009). Cell Cycle-dependent Deacetylation of Telomeric Histone H3 Lysine K56 by Human SIRT6. Cell Cycle 8, 2664-2666. doi:10.4161/cc.8.16.9367

Milne, J. C., Lambert, P. D., Schenk, S., Carney, D. P., Smith, J. J., Gagne, D. J., et al. (2007). Small Molecule Activators of SIRT1 as Therapeutics for the Treatment of Type 2 Diabetes. Nature 450, 712-716. doi:10.1038/nature06261

Moniot, S., Forgione, M., Lucidi, A., Hailu, G. S., Nebbioso, A., Carafa, V., et al. (2017). Development of 1,2,4-Oxadiazoles as Potent and Selective Inhibitors of the Human Deacetylase Sirtuin 2: Structure-Activity Relationship, X-ray Crystal Structure, and Anticancer Activity. J. Med. Chem. 60, 2344-2360. doi:10.1021/acs.jmedchem.6b01609

Morris, B. J. (2013). Seven Sirtuins for Seven Deadly Diseases of Aging. Free Radic. Biol. Med. 56, 133-171. doi:10.1016/j.freeradbiomed.2012.10.525

Muscolini, M., Castiello, L., Palermo, E., Zevini, A., Ferrari, M., Olagnier, D., et al. (2019). SIRT1 Modulates the Sensitivity of Prostate Cancer Cells to Vesicular Stomatitis Virus Oncolysis. J. Virol. 93. doi:10.1128/JVI.00626-19
Napper, A. D., Hixon, J., McDonagh, T., Keavey, K., Pons, J. F., Barker, J., et al. (2005). Discovery of Indoles as Potent and Selective Inhibitors of the Deacetylase SIRT1. J. Med. Chem. 48, 8045-8054. doi:10.1021/jm050522v

Nguyen, G. T., Schaefer, S., Gertz, M., Weyand, M., and Steegborn, C. (2013). Structures of Human Sirtuin 3 Complexes with ADP-Ribose and with Carba-Nad+ and SRT1720: Binding Details and Inhibition Mechanism. Acta Crystallogr. D Biol. Crystallogr. 69, 1423-1432. doi:10.1107/ S0907444913015448

Nikseresht, S., Khodagholi, F., and Ahmadiani, A. (2019). Protective Effects of Ex-527 on Cerebral Ischemia-Reperfusion Injury through Necroptosis Signaling Pathway Attenuation. J. Cell. Physiol. 234, 1816-1826. doi:10.1002/jcp.27055

Nishida, Y., Rardin, M. J., Carrico, C., He, W., Sahu, A. K., Gut, P., et al. (2015). SIRT5 Regulates Both Cytosolic and Mitochondrial Protein Malonylation with Glycolysis as a Major Target. Mol. Cell 59, 321-332. doi:10.1016/ j.molcel.2015.05.022

North, B. J., and Verdin, E. (2007). Interphase Nucleo-Cytoplasmic Shuttling and Localization of SIRT2 during Mitosis. PLoS One 2, e784. doi:10.1371/ journal.pone.0000784

Oon, C. E., Strell, C., Yeong, K. Y., Östman, A., and Prakash, J. (2015). SIRT1 Inhibition in Pancreatic Cancer Models: Contrasting Effects In Vitro and In Vivo. Eur. J. Pharmacol. 757, 59-67. doi:10.1016/j.ejphar.2015.03.064

Ota, H., Tokunaga, E., Chang, K., Hikasa, M., Iijima, K., Eto, M., et al. (2006). Sirt1 Inhibitor, Sirtinol, Induces Senescence-like Growth Arrest with Attenuated Ras-MAPK Signaling in Human Cancer Cells. Oncogene 25, 176-185. doi:10.1038/sj.onc.1209049

Outeiro, T. F., Kontopoulos, E., Altmann, S. M., Kufareva, I., Strathearn, K. E., Amore, A. M., et al. (2007). Sirtuin 2 Inhibitors rescue Alpha-SynucleinMediated Toxicity in Models of Parkinson's Disease. Science 317, 516-519. doi:10.1126/science. 1143780

Pacholec, M., Bleasdale, J. E., Chrunyk, B., Cunningham, D., Flynn, D., Garofalo, R. S., et al. (2010). SRT1720, SRT2183, SRT1460, and Resveratrol Are Not Direct Activators of SIRT1. J. Biol. Chem. 285, 8340-8351. doi:10.1074/jbc.M109.088682

Pannek, M., Simic, Z., Fuszard, M., Meleshin, M., Rotili, D., Mai, A., et al. (2017). Crystal Structures of the Mitochondrial Deacylase Sirtuin 4 Reveal Isoformspecific Acyl Recognition and Regulation Features. Nat. Commun. 8, 1513. doi:10.1038/s41467-017-01701-2

Parenti, M. D., Grozio, A., Bauer, I., Galeno, L., Damonte, P., Millo, E., et al. (2014). Discovery of Novel and Selective SIRT6 Inhibitors. J. Med. Chem. 57, 4796-4804. doi:10.1021/jm500487d

Plaitakis, A., Kalef-Ezra, E., Kotzamani, D., Zaganas, I., and Spanaki, C. (2017). The Glutamate Dehydrogenase Pathway and its Roles in Cell and Tissue Biology in Health and Disease. Biology (Basel) 6, 11. doi:10.3390/biology6010011

Portmann, S., Fahrner, R., Lechleiter, A., Keogh, A., Overney, S., Laemmle, A., et al. (2013). Antitumor Effect of SIRT1 Inhibition in Human HCC Tumor Models In Vitro and In Vivo. Mol. Cancer Ther. 12, 499-508. doi:10.1158/1535-7163.MCT12-0700

Prozorovski, T., Schulze-Topphoff, U., Glumm, R., Baumgart, J., Schröter, F., Ninnemann, O., et al. (2008). Sirt1 Contributes Critically to the Redoxdependent Fate of Neural Progenitors. Nat. Cell Biol. 10, 385-394. doi:10.1038/ncb1700

Ren, M., Yang, X., Bie, J., Wang, Z., Liu, M., Li, Y., et al. (2020). Citrate Synthase Desuccinylation by SIRT5 Promotes colon Cancer Cell Proliferation and Migration. Biol. Chem. 401, 1031. doi:10.1515/hsz-2020-0118

Ren, N. S. X., Ji, M., Tokar, E. J., Busch, E. L., Xu, X., Lewis, D., et al. (2017). Haploinsufficiency of SIRT1 Enhances Glutamine Metabolism and Promotes Cancer Development. Curr. Biol. 27, 483-494. doi:10.1016/ j.cub.2016.12.047

Rumpf, T., Schiedel, M., Karaman, B., Roessler, C., North, B. J., Lehotzky, A., et al. (2015). Selective Sirt2 Inhibition by Ligand-Induced Rearrangement of the Active Site. Nat. Commun. 6, 6263. doi:10.1038/ncomms7263

Safari, F., Shekarforoosh, S., Hashemi, T., Namvar Aghdash, S., Fekri, A., and Safari, F. (2017). Sirtinol Abrogates Late Phase of Cardiac Ischemia Preconditioning in Rats. J. Physiol. Sci. 67, 515-522. doi:10.1007/s12576-016-0483-y

Salehi, B., Mishra, A. P., Nigam, M., Sener, B., Kilic, M., Sharifi-Rad, M., et al. (2018). Resveratrol: A Double-Edged Sword in Health Benefits. Biomedicines 6, 91. doi:10.3390/biomedicines6030091 
Sauve, A. A., Celic, I., Avalos, J., Deng, H., Boeke, J. D., and Schramm, V. L. (2001). Chemistry of Gene Silencing: the Mechanism of NAD+-dependent Deacetylation Reactions. Biochemistry 40, 15456-15463.

Sauve, A. A., Wolberger, C., Schramm, V. L., and Boeke, J. D. (2006). The Biochemistry of Sirtuins. Annu. Rev. Biochem. 75, 435-465. doi:10.1146/ annurev.biochem.74.082803.133500

Schnekenburger, M., Goffin, E., Lee, J. Y., Jang, J. Y., Mazumder, A., Ji, S., et al. (2017). Discovery and Characterization of R/S-N-3-Cyanophenyl-N'-(6-tertbutoxycarbonylamino-3,4-dihydro-2,2-dimethyl-2H-1-benzopyran-4-yl)urea, a New Histone Deacetylase Class III Inhibitor Exerting Antiproliferative Activity against Cancer Cell Lines. J. Med. Chem. 60, 4714-4733. doi:10.1021/acs.jmedchem.7b00533

Sebastián, C., Zwaans, B. M., Silberman, D. M., Gymrek, M., Goren, A., Zhong, L., et al. (2012). The Histone Deacetylase SIRT6 Is a Tumor Suppressor that Controls Cancer Metabolism. Cell 151, 1185-1199. doi:10.1016/ j.cell.2012.10.047

Seifert, T., Malo, M., Kokkola, T., Engen, K., Fridén-Saxin, M., Wallén, E. A., et al. (2014). Chroman-4-one- and Chromone-Based Sirtuin 2 Inhibitors with Antiproliferative Properties in Cancer Cells. J. Med. Chem. 57, 9870-9888. doi:10.1021/jm500930h

Serrano, L., Martínez-Redondo, P., Marazuela-Duque, A., Vazquez, B. N., Dooley, S. J., Voigt, P., et al. (2013). The Tumor Suppressor SirT2 Regulates Cell Cycle Progression and Genome Stability by Modulating the Mitotic Deposition of H4K20 Methylation. Genes Dev. 27, 639-653. doi:10.1101/gad.211342.112

Shah, A. A., Ito, A., Nakata, A., and Yoshida, M. (2016). Identification of a Selective SIRT2 Inhibitor and its Anti-breast Cancer Activity. Biol. Pharm. Bull 39, 1739-1742. doi:10.1248/bpb.b16-00520

Shang, J. L., Ning, S. B., Chen, Y. Y., Chen, T. X., and Zhang, J. (2021). MDL-800, an Allosteric Activator of SIRT6, Suppresses Proliferation and Enhances EGFRTKIs Therapy in Non-small Cell Lung Cancer. Acta Pharmacol. Sin. 42, 120-131. doi:10.1038/s41401-020-0442-2

She, D. T., Wong, L. J., Baik, S. H., and Arumugam, T. V. (2018). SIRT2 Inhibition Confers Neuroprotection by Downregulation of FOXO3a and MAPK Signaling Pathways in Ischemic Stroke. Mol. Neurobiol. 55, 9188-9203. doi:10.1007/ s12035-018-1058-0

Shi, L., Yan, H., An, S., Shen, M., Jia, W., Zhang, R., et al. (2019). SIRT5-mediated Deacetylation of LDHB Promotes Autophagy and Tumorigenesis in Colorectal Cancer. Mol. Oncol. 13, 358-375. doi:10.1002/1878-0261.12408

Simic, P., Williams, E. O., Bell, E. L., Gong, J. J., Bonkowski, M., and Guarente, L. (2013). SIRT1 Suppresses the Epithelial-To-Mesenchymal Transition in Cancer Metastasis and Organ Fibrosis. Cell Rep. 3, 1175-1186. doi:10.1016/ j.celrep.2013.03.019

Smith, B. C., and Denu, J. M. (2007). Mechanism-Based Inhibition of Sir2 Deacetylases by Thioacetyl-Lysine Peptide. Biochemistry 46, 14478-14486. doi:10.1021/bi7013294

Sociali, G., Galeno, L., Parenti, M. D., Grozio, A., Bauer, I., Passalacqua, M., et al. (2015). Quinazolinedione SIRT6 Inhibitors Sensitize Cancer Cells to Chemotherapeutics. Eur. J. Med. Chem. 102, 530-539. doi:10.1016/ j.ejmech.2015.08.024

Sociali, G., Magnone, M., Ravera, S., Damonte, P., Vigliarolo, T., Von Holtey, M., et al. (2017). Pharmacological Sirt6 Inhibition Improves Glucose Tolerance in a Type 2 Diabetes Mouse Model. FASEB J. 31, 3138-3149. doi:10.1096/ fj.201601294R

Solomon, J. M., Pasupuleti, R., Xu, L., McDonagh, T., Curtis, R., DiStefano, P. S., et al. (2006). Inhibition of SIRT1 Catalytic Activity Increases P53 Acetylation but Does Not Alter Cell Survival Following DNA Damage. Mol. Cell. Biol. 26, 28-38. doi:10.1128/MCB.26.1.28-38.2006

Spiegelman, N. A., Hong, J. Y., Hu, J., Jing, H., Wang, M., Price, I. R., et al. (2019). A Small-Molecule SIRT2 Inhibitor that Promotes K-Ras4a Lysine Fatty-Acylation. ChemMedChem 14, 744-748. doi:10.1002/cmdc.201800715

Spiegelman, N. A., Price, I. R., Jing, H., Wang, M., Yang, M., Cao, J., et al. (2018). Direct Comparison of SIRT2 Inhibitors: Potency, Specificity, Activitydependent Inhibition, and On-Target Anticancer Activities. ChemMedChem. 13, 1890-1894. doi:10.1002/cmdc.201800391

Sundaresan, N. R., Vasudevan, P., Zhong, L., Kim, G., Samant, S., Parekh, V., et al. (2012). The Sirtuin SIRT6 Blocks IGF-Akt Signaling and Development of Cardiac Hypertrophy by Targeting C-Jun. Nat. Med. 18, 1643-1650. doi:10.1038/nm.2961
Süssmuth, S. D., Haider, S., Landwehrmeyer, G. B., Farmer, R., Frost, C., Tripepi, G., et al. (2015). An Exploratory Double-Blind, Randomized Clinical Trial with Selisistat, a SirT1 Inhibitor, in Patients with Huntington's Disease. Br. J. Clin. Pharmacol. 79, 465-476. doi:10.1111/bcp.12512

Suzuki, T., Khan, M. N., Sawada, H., Imai, E., Itoh, Y., Yamatsuta, K., et al. (2012) Design, Synthesis, and Biological Activity of a Novel Series of Human Sirtuin-2Selective Inhibitors. J. Med. Chem. 55, 5760-5773. doi:10.1021/jm3002108

Tan, Y. J., Lee, Y. T., Petersen, S. H., Kaur, G., Kono, K., Tan, S. C., et al. (2019). BZD9L1 Sirtuin Inhibitor as a Potential Adjuvant for Sensitization of Colorectal Cancer Cells to 5-fluorouracil. Ther. Adv. Med. Oncol. 11, 1758835919878977. doi:10.1177/1758835919878977

Tan, Y. J., Lee, Y. T., Yeong, K. Y., Petersen, S. H., Kono, K., Tan, S. C., et al. (2018). Anticancer Activities of a Benzimidazole Compound through Sirtuin Inhibition in Colorectal Cancer. Future Med. Chem. 10, 2039-2057. doi:10.4155/fmc2018-0052

Tanno, M., Sakamoto, J., Miura, T., Shimamoto, K., and Horio, Y. (2007). Nucleocytoplasmic Shuttling of the NAD+-dependent Histone Deacetylase SIRT1. J. Biol. Chem. 282, 6823-6832. doi:10.1074/jbc.M609554200

Tasselli, L., Xi, Y., Zheng, W., Tennen, R. I., Odrowaz, Z., Simeoni, F., et al. (2016). SIRT6 Deacetylates H3K18ac at Pericentric Chromatin to Prevent Mitotic Errors and Cellular Senescence. Nat. Struct. Mol. Biol. 23, 434-440. doi:10.1038/ nsmb.3202

Taylor, D. M., Balabadra, U., Xiang, Z., Woodman, B., Meade, S., Amore, A., et al. (2011). A Brain-Permeable Small Molecule Reduces Neuronal Cholesterol by Inhibiting Activity of Sirtuin 2 Deacetylase. ACS Chem. Biol. 6, 540-546. doi:10.1021/cb100376q

Teng, Y. B., Jing, H., Aramsangtienchai, P., He, B., Khan, S., Hu, J., et al. (2015). Efficient Demyristoylase Activity of SIRT2 Revealed by Kinetic and Structural Studies. Sci. Rep. 5, 8529. doi:10.1038/srep08529

Tong, Z., Wang, M., Wang, Y., Kim, D. D., Grenier, J. K., Cao, J., et al. (2017). SIRT7 Is an RNA-Activated Protein Lysine Deacylase. ACS Chem. Biol. 12, 300-310. doi:10.1021/acschembio.6b00954

Torrens-Mas, M., Oliver, J., Roca, P., and Sastre-Serra, J. (2017). SIRT3: Oncogene and Tumor Suppressor in Cancer. Cancers (Basel) 9, 90. doi:10.3390/ cancers 9070090

Trammell, S. A., Schmidt, M. S., Weidemann, B. J., Redpath, P., Jaksch, F., Dellinger, R. W., et al. (2016). Nicotinamide Riboside Is Uniquely and Orally Bioavailable in Mice and Humans. Nat. Commun. 7, 12948. doi:10.1038/ncomms12948

Vikram, A., Lewarchik, C. M., Yoon, J. Y., Naqvi, A., Kumar, S., Morgan, G. M., et al. (2017). Sirtuin 1 Regulates Cardiac Electrical Activity by Deacetylating the Cardiac Sodium Channel. Nat. Med. 23, 361-367. doi: $10.1038 / \mathrm{nm} .4284$

Wang, B., Zhang, Y., Cao, W., Wei, X., Chen, J., and Ying, W. (2016). SIRT2 Plays Significant Roles in Lipopolysaccharides-Induced Neuroinflammation and Brain Injury in Mice. Neurochem. Res. 41, 2490-2500. doi:10.1007/s11064016-1981-2

Wang, M., and Lin, H. (2021). Understanding the Function of Mammalian Sirtuins and Protein Lysine Acylation. Annu. Rev. Biochem. 90, 245. doi:10.1146/ annurev-biochem-082520-125411

Wang, T., Li, X., and Sun, S. L. (2020). EX527, a Sirt-1 Inhibitor, Induces Apoptosis in Glioma via Activating the P53 Signaling Pathway. Anticancer Drugs 31, 19-26. doi:10.1097/CAD.0000000000000824

Wei, L., Liu, B., Yao, Z., Yuan, T., Wang, C., Zhang, R., et al. (2021). Sirtuin 1 Inhibitor EX527 Suppresses Morphine-Induced Behavioral Sensitization. Neurosci. Lett. 744, 135599. doi:10.1016/j.neulet.2020.135599

Wu, D., Lu, W., Wei, Z., Xu, M., and Liu, X. (2018). Neuroprotective Effect of Sirt2specific Inhibitor AK-7 against Acute Cerebral Ischemia Is P38 Activation-dependent in Mice. Neuroscience 374, 61-69. doi:10.1016/j.neuroscience.2018.01.040

Wu, Z., Zhang, Y., Zhang, Y., and Zhao, P. (2020). Sirtuin 2 Inhibition Attenuates Sevoflurane-Induced Learning and Memory Deficits in Developing Rats via Modulating Microglial Activation. Cell Mol. Neurobiol. 40, 437-446. doi:10.1007/s10571-019-00746-9

Xiangyun, Y., Xiaomin, N., Linping, G., Yunhua, X., Ziming, L., Yongfeng, Y., et al. (2017). Desuccinylation of Pyruvate Kinase M2 by SIRT5 Contributes to Antioxidant Response and Tumor Growth. Oncotarget 8, 6984-6993. doi:10.18632/oncotarget.14346 
Xu, Y., Qin, Q., Chen, R., Wei, C., and Mo, Q. (2018). SIRT1 Promotes Proliferation, Migration, and Invasion of Breast Cancer Cell Line MCF-7 by Upregulating DNA Polymerase delta1 (POLD1). Biochem. Biophys. Res. Commun. 502, 351-357. doi:10.1016/j.bbrc.2018.05.164

Yang, H., Chen, Y., Jiang, Y., Wang, D., Yan, J., and Zhou, Z. (2020). TP53 Mutation Influences the Efficacy of Treatment of Colorectal Cancer Cell Lines with a Combination of Sirtuin Inhibitors and Chemotherapeutic Agents. Exp. Ther. Med. 20, 1415-1422. doi:10.3892/etm.2020.8818

Yang, L. L., Wang, H. L., Zhong, L., Yuan, C., Liu, S. Y., Yu, Z. J., et al. (2018). X-ray crystal Structure Guided Discovery of New Selective, SubstrateMimicking Sirtuin 2 Inhibitors that Exhibit Activities against Non-small Cell Lung Cancer Cells. Eur. J. Med. Chem. 155, 806-823. doi:10.1016/ j.ejmech.2018.06.041

Yang, M. H., Laurent, G., Bause, A. S., Spang, R., German, N., Haigis, M. C., et al. (2013). HDAC6 and SIRT2 Regulate the Acetylation State and Oncogenic Activity of Mutant K-RAS. Mol. Cancer Res. 11, 1072-1077. doi:10.1158/15417786.MCR-13-0040-T

Yang, Y., Hou, H., Haller, E. M., Nicosia, S. V., and Bai, W. (2005). Suppression of FOXO1 Activity by FHL2 through SIRT1-Mediated Deacetylation. EMBO J. 24, 1021-1032. doi:10.1038/sj.emboj.7600570

Yeung, F., Hoberg, J. E., Ramsey, C. S., Keller, M. D., Jones, D. R., Frye, R. A., et al. (2004). Modulation of NF-kappaB-dependent Transcription and Cell Survival by the SIRT1 Deacetylase. EMBO J. 23, 2369-2380. doi:10.1038/sj.emboj.7600244

Yoon, Y. K., Ali, M. A., Wei, A. C., Choon, T. S., Shirazi, A. N., and Parang, K. (2015). Discovery of a Potent and Highly Fluorescent Sirtuin Inhibitor. Med. Chem. Commun. 6, 1857-1863. doi:10.1039/C5MD00307E

You, W., Rotili, D., Li, T. M., Kambach, C., Meleshin, M., Schutkowski, M., et al. (2017). Structural Basis of Sirtuin 6 Activation by Synthetic Small Molecules. Angew. Chem. Int. Ed. Engl. 56, 1007-1011. doi:10.1002/anie.201610082

Yousafzai, N. A., Zhou, Q., Xu, W., Shi, Q., Xu, J., Feng, L., et al. (2019). SIRT1 Deacetylated and Stabilized XRCC1 to Promote Chemoresistance in Lung Cancer. Cell Death Dis. 10, 363. doi:10.1038/s41419-019-1592-3

Yuan, H., He, M., Cheng, F., Bai, R., da Silva, S. R., Aguiar, R. C., et al. (2017). Tenovin-6 Inhibits Proliferation and Survival of Diffuse Large B-Cell Lymphoma Cells by Blocking Autophagy. Oncotarget 8, 14912-14924. doi:10.18632/oncotarget.14741

Zhang, G., Liu, Z., Qin, S., and Li, K. (2015). Decreased Expression of SIRT6 Promotes Tumor Cell Growth Correlates Closely with Poor Prognosis of Ovarian Cancer. Eur. J. Gynaecol. Oncol. 36, 629-632.

Zhang, Q. J., Wang, Z., Chen, H. Z., Zhou, S., Zheng, W., Liu, G., et al. (2008). Endothelium-specific Overexpression of Class III Deacetylase SIRT1 Decreases Atherosclerosis in Apolipoprotein E-Deficient Mice. Cardiovasc. Res. 80, 191-199. doi:10.1093/cvr/cvn224
Zhang, R., Wang, C., Tian, Y., Yao, Y., Mao, J., Wang, H., et al. (2019). SIRT5 Promotes Hepatocellular Carcinoma Progression by Regulating Mitochondrial Apoptosis. J. Cancer 10, 3871-3882. doi:10.7150/jca.31266

Zhang, X., Khan, S., Jiang, H., Antonyak, M. A., Chen, X., Spiegelman, N. A., et al. (2016). Identifying the Functional Contribution of the DefattyAcylase Activity of SIRT6. Nat. Chem. Biol. 12, 614-620. doi:10.1038/ nchembio. 2106

Zhang, X., Spiegelman, N. A., Nelson, O. D., Jing, H., and Lin, H. (2017). SIRT6 Regulates Ras-Related Protein R-Ras2 by Lysine Defatty-Acylation. eLife 6, e25158. doi:10.7554/eLife.25158

Zhao, D., Zou, S. W., Liu, Y., Zhou, X., Mo, Y., Wang, P., et al. (2013). Lysine5 Acetylation Negatively Regulates Lactate Dehydrogenase A and Is Decreased in Pancreatic Cancer. Cancer Cell 23, 464-476. doi:10.1016/ j.ccr.2013.02.005

Zhao, Y., Yang, J., Liao, W., Liu, X., Zhang, H., Wang, S., et al. (2010). Cytosolic FoxO1 Is Essential for the Induction of Autophagy and Tumour Suppressor Activity. Nat. Cell Biol. 12, 665-675. doi:10.1038/ncb2069

Zhou, W., Ni, T. K., Wronski, A., Glass, B., Skibinski, A., Beck, A., et al. (2016). The SIRT2 Deacetylase Stabilizes Slug to Control Malignancy of Basal-like Breast Cancer. Cell Rep. 17, 1302-1317. doi:10.1016/j.celrep.2016.10.006

Zhou, X. M., Zhang, X., Zhang, X. S., Zhuang, Z., Li, W., Sun, Q., et al. (2014). SIRT1 Inhibition by Sirtinol Aggravates Brain Edema after Experimental Subarachnoid Hemorrhage. J. Neurosci. Res. 92, 714-722. doi:10.1002/ jnr.23359

Conflict of Interest: HL is a founder and consultant for Sedec Therapeutics.

The remaining author declares that the research was conducted in the absence of any commercial or financial relationships that could be construed as a potential conflict of interest.

Publisher's Note: All claims expressed in this article are solely those of the authors and do not necessarily represent those of their affiliated organizations, or those of the publisher, the editors and the reviewers. Any product that may be evaluated in this article, or claim that may be made by its manufacturer, is not guaranteed or endorsed by the publisher.

Copyright (c) 2021 Hong and Lin. This is an open-access article distributed under the terms of the Creative Commons Attribution License (CC BY). The use, distribution or reproduction in other forums is permitted, provided the original author(s) and the copyright owner(s) are credited and that the original publication in this journal is cited, in accordance with accepted academic practice. No use, distribution or reproduction is permitted which does not comply with these terms. 